\title{
NBSIR 75.774 \\ Calibration of Kerr Systems Used to Measure High Voltage Pulses
}

Robert E. Hebner, Jr.

Electricity Division

Institute for Basic Standards

National Bureau of Standards

August 7, 1975

Final Report on

Sandia Corporation Order No. 51-9312

Sandia Technical Consultant: S. R. Booker, Org. 9532

Sandia Contracting Representative: J. G. Boyes, Org. 4361

Prepared for

Sandia Corporation

Bldg. 894, Kirtland AFB

East Albuquerque, New Mexico 87115 



\section{CALIBRATION OF KERR SYSTEMS USED TO MEASURE HIGH VOLTAGE PULSES}

Robert E. Hebner, Jr.

Electricity Division

Institute for Basic Standards

National Bureau of Standards

August 7. 1975

Final Report on

Sandia Corporation Order No. 51-9312

Sandia Technical Consultant: S. R. Booker, Org. 9532

Sandia Contracting Representative: J. G. Boyes, Org. 4361

Prepared for

Sandia Corporation

Bldg. 894, Kirtland AFB

East Albuquerque, New Mexico 87115

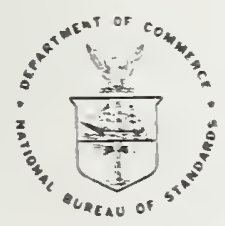

U.S. DEPARTMENT OF COMMERCE, Rogers C.B. Morton, Secretary James A. Baker, III, Under Secretary

Dr. Betsy Ancker-Johnson, Assistant Secretary for Science and Technology

NATIONAL BUREAU OF STANDARDS, Ernest Ambler, Acting Director 

TABLE OF CONTENTS

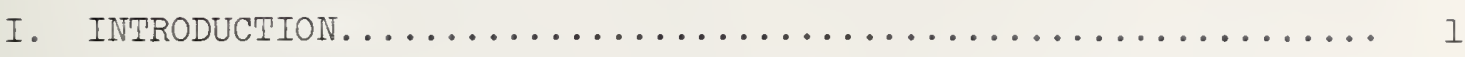

II. CALIBRATION OF DEVICES USED TO MEASURE

HIGH VOLTAGE PULSES........................... 2

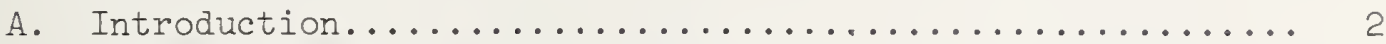

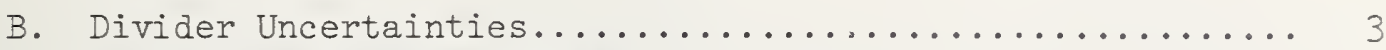

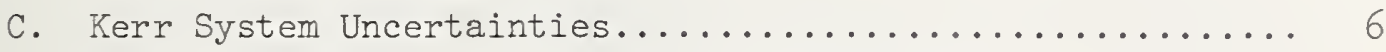

D. Low Frequency Calibration of a Kerr System............ 8

1. Introduction........................... 8

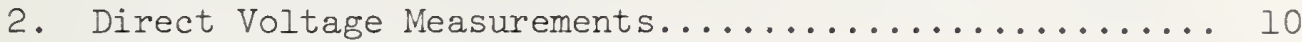

3. Alternating Voltage Measurements................... 15

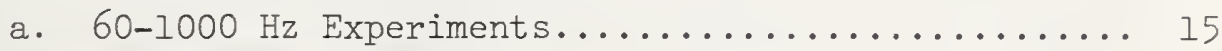

b. Measurements at $9,000-20,000 \mathrm{~Hz} \ldots \ldots \ldots \ldots$

4. Pulse Measurements........................ 20

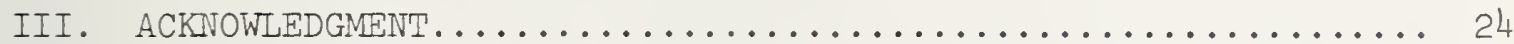

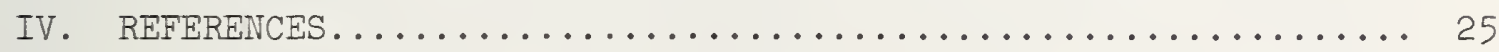

APPENDIX 1 "Improved Techniques for the Measurement

of High Voltage Impulses Using the

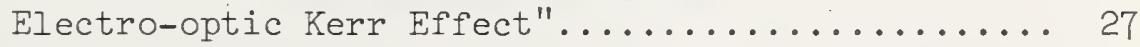

APPENDIX 2 "Electric Field Distributions and Space

Charge Behavior in Nitrobenzene under

Low Frequency Alternating Voltage"............ 41 



\section{Introduction}

The purpose of this work is to define, develop and refine techniques for calibrating pulse voltage measurement systems, particularly those based on the electro-optic Kerr effect. The uncertainty of the calibration is to be no larger than $\pm 0.5 \%$. This calibration is to be performed at operating voltage levels and not require use of a divider network.

Substantial progress has been made toward this goal. The approach exploits the assumed frequency independence of the Kerr coefficient of nitrobenzene. Theoretically, the Kerr coefficient should exhibit the same frequency dependence as the relative permittivity. Measurements have shown the relative permittivity to be approximately frequency independent over the frequency range from direct voltage to $10^{9} \mathrm{~Hz}$. Recognition of this has prompted speculation that a Kerr system could be calibrated under high voltage at a convenient frequency--direct or $60 \mathrm{~Hz}$ alternating.voltage, for example--and the calibration would be valid for pulse measurements.

The realization of this calibration approach has been hampered by the fact that the electric field distribution, in the liquid exhibiting the electro-optic Kerr effect, is itself frequency dependent. The frequency dependence of the electric field distribution is caused by space charge in the birefringent fluid. This space charge, having a finite mobility, reacts to the time-varying applied voltage. The spatial distribution of the charge carriers, and therefore the spatial distribution of the electric field, will then depend on a variety of factors including the nature of the carriers, the frequency and magnitude of the applied voltage, the viscosity of the birefringent fluid, and the geometry of the Kerr cell. Work at the Electrostatics Laboratory of the National Center for Scientific Research, Grenoble, France, the National Bureau of Standards, and Sandia Corporation indicates that the space charge density can be reduced by purification of the fluid. It cannot, however, be reduced to such a level that it becomes an insignificant perturbation under low frequency alternating voltage.

This report describes the present best comparison of cell calibration under direct voltage with calibration under low frequency alternating voltage and calibration under pulsed high voltage. The results under all three types of waveforms agree to within $\pm 0.5 \%$. From these results it can be inferred that it is feasible to use an electro-optic Kerr system as an independent, and possibly more accurate, device against which to calibrate other pulse voltage measurement systems.

In addition to this discussion of Kerr system calibration, the report contains two appendices presenting topics important for the efficient operation of a pulse voltage measurement system based on the electrooptic Kerr effect. 
The first appendix to this report contains a discussion of an improved technique for accumulating and analyzing the data obtained from a Kerr system. In this technique the voltage signal from the photomultiplier is digitized and stored using a commercially available transient recorder. The data is then transmitted to a computer which determines the voltage as a function of time. Relevant pulse parameters such as peak voltage and risetime are then calculated and displayed. This permits the immediate and accurate extraction of pulse parameters from the Kerr response.

The second appendix is a reprint of an article published in the 1973 Annual Report on the Conference on Electrical Insulation and Dielectric Phenomena. This reprint describes work, partially supported by Sandia Corporation, directed toward the prediction and control of the space charge effects in nitrobenzene-filled Kerr cells.

\section{Calibration of Devices Used to Measure High Voltage PuIses}

\section{A. Introduction}

The accurate measurement of high voltage pulses places conflicting demands on the measurement system. High voltage levels require large geometry to provide adequate electrical insulation. The fast risetimes of the pulses--with the attendant wide frequency range of interest--are most accurately measured using a compact, geometrically well-defined system. As a consequence, measurement systems designed to measure high voltage pulses represent a compromise between frequency response and high voltage protection. Accurate measurement systems are, therefore, generally optimized to faithfully reproduce the waveform of an individual generator rather than designed as wide-range, general-purpose instruments. 1

This fact is acknowledged in the standard procedures for the calibration of pulse dividers. Two approaches which permit the prediction of the response of a measurement system are recognized. One is a comprehensive approach--both the frequency response and the voltage dependence of the divider ratio are experimentally determined so that the magnitude and waveshape of the high voltage pulse can be calculated from the divider output. A second approach is valid when the primary interest is in one type of pulse and when the approximate waveshape and magnitude of the pulse is known. In this case, the divider to be calibrated is connected in parallel with a measuring device having a known response. The "unknown" device is then calibrated against the "known" device as the two are used to measure the same applied pulse. This second approach has been adopted by NBS for the calibration of pulse systems submitted by Sandia Corporation.

Part B of this section of the report discusses uncertainties inherent in the measurement of high voltage pulses using a conventional divider, while part $C$ discusses the uncertainties when this same measurement is made using a Kerr system. Drawing on these for background, part D 
presents the results of Kerr system calibration under direct, low frequency alternating and pulsed high voltage.

\section{B. Divider Uncertainties}

Determination of the peak value of a high voltage pulse from measured divider response makes use of the following relationship:

$$
\mathrm{V}_{\mathrm{p}}=\alpha \mathrm{V}_{\ell}
$$

In this equation, $V_{p}$ is the peak value of the high voltage, $\alpha$ is the

divider ratio and $v_{l}$ is the measured value of the peak of the relatively low voltage presented to the input terminals of the measuring device. In this discussion, an artificial distinction is being made between the divider and the measuring device. For example, assume that one has a divider connected to a high voltage pulse generator, an oscilloscope to measure the low voltage output from the divider, and a cable connecting the two. The value of the divider ratio which should be used in Eq. I will be determined by all three of these devices. The measured value of the low voltage, $V_{l}$, is determined only by the oscilloscope. The significance of this is that care must be taken in the assessment of overall measurement uncertainty if the discrete components of the system are calibrated rather than the system calibrated as a unit.

From Eq. 1, the uncertainty in the measurement can be expressed

$$
\Delta \mathrm{V}_{\mathrm{p}} / \mathrm{V}_{\mathrm{p}}= \pm \Delta \alpha / \alpha \pm \Delta \mathrm{V}_{\ell} / \mathrm{V}_{\ell}
$$

The quantity $\Delta \mathrm{V}_{\ell} / \mathrm{V}_{\ell}$ is typically 0.01-0.05. If, however, a suppressed zero (slideback) measurement technique is used, its value can be as low as 0.001. Similarly, $\Delta \alpha / \alpha$ is typically 0.01-0.05. The factors which contribute to this uncertainty can be understood from an analysis of the following published list of the sources of error in pulse measurement $s^{3,4}$ :

1. residual inductance in any resistance or capacitance element;

2. stray capacitance - (A) from any section of the divider to ground or a grounded object, (B) from any section of the divider to high voltage parts of the supply and test circuit, and (C) between sections of the divider;

3. impedance drop in the lead from the point at which the high voltage is to be measured to the high voltage end of the divider;

4. impedance drop in the ground return lead from the divider due to either extraneous ground currents flowing in this lead or to the divider current; 
5. oscillations set up in the divider circuit caused by capacitance from the divider high voltage terminal to ground and lead inductance.

Although the first source of error is intrinsic to the divider, the other four error sources depend upon the arrangement of the. experimental apparatus. It then follows that four of the five sources of error depend upon the experimental set-up and so will be laboratory dependent but relatively independent of the divider.

Two implications of this fact should be discussed further. One is that the use of a calibrated divider does not assure accurate measurement in the same sense as, for example, the use of a calibrated digital voltmeter assures accurate measurement of low direct voltage. In the latter case, user convenience features have been incorporated into the device which make measurement errors due to undetected operator errors relatively unlikely. In the former case, however, ground current errors or capacitive coupling between high and low voltage components can permit consistent, reproducible, but erroneous measurements of the magnitude and shape of the high voltage pulse. A calibrated pulse measuring device is most often used to verify that a measurement system is being used correctly. That is, a calibrated device--a resistor divider whose ratio is known, for example--is placed in the pulse generating-measuring circuit under test. Comparison of the high voltage pulse as measured by the calibrated device and by the system under test provides a measure of accuracy of the unknown device.

The second implication, which is an extension of the first, is that a program of comparison of measurements among various laboratories can insure that undetected systematic measurement errors have not been introduced into a measurement system.

As was mentioned previously, the calibration technique consists of comparing the output of the device under test with the output of calibrated devices when a high voltage pulse is applied. The two calibrated devices used by NBS are a resistor voltage divider and a Kerr system. The possible errors associated with the divider include the list presented earlier plus any additional uncertainty introduced by the device used to measure the low voltage signal. The divider is constructed of counterwound resistors to minimize any residual

inductance. The effects of stray capacitance are kept as small as possible in two ways. First, the resistance of the divider is only $500 \Omega$. This low resistance helps to keep the RC time constant--due

to the divider's resistance and any stray capacitance--short compared to any time interval during which a significant variation in the voltage waveform occurs, i.e., less than about $100 \mathrm{~ns}$. The second way to minimize stray capacitance errors is to make measurements only during a portion of the pulse when its time rate of change is small. The applied voltage pulse is an approximately rectangular pulse with rise and fall times of about $l \mu s$ and a duration of about $10 \mu \mathrm{s}$. Measurements are made near the trailing end of this pulse so that a 
"steady-state" condition is attained prior to and during the measurement.

Errors introduced by induced currents during the measurement can be made acceptably (i.e., undetectably) small by appropriate arrangement of the high and low voltage circuitry. Particular attention is paid to the grounding procedures. Partial verification that the error is minimized is obtained in the following manner:
a. the circuit is assembled in exactly the configuration in which it is to be used;
b. the low voltage output of the divider is shorted to ground;
c. the pulse generator is fired and the response of the system is recorded on an oscillogram.

It can be correctly inferred from the first step that any modification of the high voltage circuit requires a reverification that induced or ground currents are not causing unacceptably large errors. The sensitivity to geometry can be appreciated by a consideration of the sources of error which can contribute to a non-zero reading under these conditions.

The first, and in our laboratory, the most common, is the voltage difference due to the non-zero impedance between various grounds in the circuit. This phenomenon is sometimes called "ground current error." The error is indicated as an apparent potential difference between the input and the ground connection of the oscilloscope. If there is, for example, a small resistance between the ground connection of the oscilloscope and the ground connection of the divider, the large current associated with the high voltage pulse can lead to a significant voltage to be measured at the oscilloscope. It is selfevident that the magnitude of this voltage is dependent upon the location of ground connections and the length of the interconnecting cable between the divider and the oscilloscope.

A second geometry-dependent source of an error voltage is the mutual inductance in the system. In a Marx-type circuit, such as is used at NBS to generate voltage pulses, there is a high current pulse as well as a high voltage pulse. The associated magnetic field induces voltage pulses in any loops within or adjacent to the high voltage circuit. The magnitude of this induced voltage is very sensitive to the geometry of the high voltage circuit. A third geometry dependent effect which must be,considered is the capacitive coupling among various components of the circuit. The final error source which could be geometry dependent is radiated electromagnetic interference. The primary source of this signal is electrical breakdown, either intentional as in the operation of the control spark gaps or unintentional such as corona in the impulse generator at full charging voltage. Although the source of 
this signal is relatively insensitive to the configuration of the apparatus, its effect on the measurement can be minimized by appropriate placement of sensitive detectors.

To verify that the sum of the errors from all of these sources is negligible, it is necessary to perform a measurement in a system that approximates as closely as possible the measurement situation. In this work, this is accomplished by placing a short circuit in parallel with, and immediately adjacent to, the low resistance arm of the resistor divider. The short circuit is contained in a coupler which is used between the signal cable and the output terminal of the divider.

To determine the errors remaining, the high voltage generator is fired with the low impedance arm of the divider shorted. The errors are assumed to be sufficiently small if the voltage measured using the oscilloscope is less than $0.1 \%$ of the voltage to be measured under normal operation.

\section{Kerr System Uncertainties}

Uncertainties inherent in pulse voltage measurement using the Kerr effect can conveniently be discussed within the framework of equations which define the Kerr effect. The Kerr effect is described by the relationship

$$
n_{11}-n_{1}=\lambda B E^{2}
$$

where $n_{l 1}(1)$ is the index of refraction for light polarized parallel (perpendicular) to the direction of the applied field $\mathbb{E}, B$ is the Kerr coefficient and $\lambda$ is the wavelength of the monochromatic light traversing the Kerr cell. Eq. (3) can be used to determine the phase shift, $\phi$, between the components of the light beam polarized parallel to and perpendicular to the direction of the applied field:

$$
\phi=2 \pi \int_{0}^{L} B E^{2} d l .
$$

In Eq. (4), I is the length of the path through the applied field. It is assumed that $\mathrm{Eq}$. (4) can be rewritten

$$
\phi=\pi\left(\mathrm{V} / \mathrm{V}_{\mathrm{m}}\right)^{2}
$$

where

$$
V_{m}^{\cdot}=d /\left(2 B l^{\prime}\right)^{\frac{1}{2}}
$$


and $\mathrm{V}$ is the applied voltage. In Eq. 6, it has been assumed that the Kerr cell is a parallel-plate capacitor with plate spacing $d$. The integral in Eq. 4, has been approximated,

$$
\int_{0}^{L} B E^{2} d l \simeq B l \cdot(V / d)
$$

where $l^{\prime}$ is an effective plate length which includes the effects of fringing fields.

It is appropriate to discuss the physical significance of $\mathrm{V}$ which is named either the "cell constant" or the "half-wave voltage" ${ }^{m}$ depending upon the point of emphasis. Eq. 6 shows the origin of the term "cell constant". From this expression, it can be seen that the magnitude of $\mathrm{V}_{\mathrm{m}}$ is determined by the geometry of the cell ( $\mathrm{d}$ and $l^{\prime}$ ) and the Kerr coefficient, $B$, of the material in the cell. When the cell constant is known, Eq. 5 can be used to predict the phase shift between orthogonally polarized components of the light beam upon passage through the cell when a voltage, $V$, is applied to that cell.

The term "half-wave voltage" has a slightly different emphasis. From Eq. 5, it can be seen that when the applied voltage equals $V_{m}$, the phase shift has a magnitude $\pi$. A phase shift of magnitude $\pi$ is equivalent to a spatial shift of the origin of one of the components by a distance $\lambda / 2$. Thus $V_{m}$ is called a half-wave voltage.

The cell constant has a further significance. Calibration of a cell consists of determining the magnitude of $\mathrm{V}_{\mathrm{m}}$. Because of the

configuration of the optical components in a typical Kerr system, the cell constant corresponds to the smallest voltage which will cause a maximum in the optical transmittance through the system. So calibration consists of applying a known voltage to the cell, measuring the phase shift, and using Eq. 5--in a somewhat more convenient form--to determine the cell constant.

From Eq. (5), the uncertainty in voltage measurement can be expressed as

$$
\Delta \mathrm{V} / \mathrm{V}= \pm \Delta \mathrm{V}_{\mathrm{m}} / \mathrm{V}_{\mathrm{m}} \pm(\Delta \phi / \phi) / 2
$$

This expression simply states that the uncertainty in voltage measurement is the sum of the uncertainty in the cell's calibration and the uncertainty in the measurement of the cell's response to the applied voltage pulse. Previous work ${ }^{5}$ has shown that for an appropriately constructed cell and detection system

$$
(\Delta \phi / \phi) / 2 \ll 0.01
$$


The more significant contribution to measurement uncertainty is the uncertainty in cell calibration $\Delta \mathrm{V}_{\mathrm{m}} / \mathrm{V}_{\mathrm{m}}$. It has also been demonstrated 6 that the cell constant can be determined under pulsed high voltage for fixed temperature, wavelength and light path through the cell. The calibration technique is to connect the Kerr cell in paraliel with the divider described above and apply a high voltage pulse to the combination. The phase shift between the components of the light beam is measured as is the applied voltage. Eq. 5 can then be used to calculate $V_{m}$. If subsequent pulsed high voltage measurements are made using both the divider and now calibrated Kerr cell, it is found that the results agree to within about $0.1 \%$ of the peak voltage value. Because the estimated uncertainty of the voltage divider measurement is $\pm 1 \%$ the uncertainty of the Kerr system calibration is also approximately $\pm 1 \%$. Direct voltage measurements using the above approach have also indicated that the uncertainty in the determination of $\mathrm{V}_{\mathrm{m}}$ is not larger than $\pm 1 \%$. That is to say, $\Delta \mathrm{V}_{\mathrm{m}} / \mathrm{V}_{\mathrm{m}}$ is \pm 0.01 .

This procedure, although it has proven to be an effective method of assuring accurate pulse measurement, is somewhat less than ideal for two related reasons. One is that although calibration accuracy is maintained using two independent devices it is established through the use of a divider alone. Thus the accuracy of the Kerr system calibration depends on the accuracy of the divider calibration and the inherent experimental difficulties of divider measurements have been documented. An independent calibration of a Kerr system would be desirable to provide additional insurance against undetected systematic errors in high voltage pulse measurement.

The second point is that simultaneous measurements of the same voltage pulse using both a divider and a Kerr system have experimentally demonstrated that the Kerr system offers better measurement precision than does the divider. Thus an independent calibration of a Kerr system could result in better measurement accuracy.

An independent--of a pulse divider-calibration of a Kerr system was performed. A discussion of the calibration is the basis for the following section of this report.

\section{Low Frequency Calibration of a Kerr System}

\section{Introduction}

It has long been recognized that one of the potential benefits of a Kerr system is that it should be possible to calibrate a cell at direct or alternating voltage for use in high voltage pulse measurements. To understand why this should be possible, it is helpful to review the nature of voltage measurement using the electro-optic Kerr effect. To determine voltage from Kerr effect data, the following equation is used:

$$
I / I_{m}=\sin ^{2}\left[\pi\left(V / V_{m}\right)^{2} / 2\right]
$$


In this relationship, I is the transmittance of the optical system at a voltage level V, and Vm--the cell constant--is the lowest voltage which causes a maximum in the transmittance, $I_{m}$. Calibration of a cell consists of determining $\mathrm{V}_{\mathrm{m}}$. Once $\mathrm{V}_{\mathrm{m}}$ is known, Eq. 10 can be used to relate the optical transmittance to the applied voltage. The cell constant can be expressed in terms of the cell geometry and the Kerr coefficient of the birefringent fluid, i.e.,

$$
V_{m}=d\left(2 B \ell^{\prime}\right)^{-\frac{1}{2}}
$$

In Eq. Il, $d$ is the plate spacing, $l^{\prime}$ is the effective plate length-parallel plate geometry is assumed--and B is the Kerr coefficient. It follows from this equation that any frequency dependence of the cell constant would be due to a frequency dependence of either the Kerr coefficient of the birefringent fluid in the cell or the effective plate length $\ell$ '.

Quantitatively accurate calculations of the Kerr coefficient of polar liquids are presently unfeasible because of uncertainties in liquid structure. Insight into the sensitivity of the Kerr coefficient to variations in wavelength, temperature, frequency of the applied voltage, etc., can, however, be gained from an examination of the classical expression for the Kerr coefficient of a polar fluid?,

$$
B=\pi \rho\left(n^{2}+2\right)^{2}(\varepsilon+2)^{2}\left(\theta_{1}+\theta_{2}\right) / 27 n \lambda .
$$

In this equation, $\mathrm{n}$ is the index of refraction at the wavelength of the incident light $\lambda, \varepsilon$ is relative permittivity of the medium, and $\rho$ is the number density of the molecules. $\theta_{1}$ and $\theta_{2}$ represent expressions involving the temperature of the fluid, the static and optical polarizabilities and the dipole moment of the molecule. Previous theoretical work has shown that the temperature dependence can be explicitly expressed in the form

$$
\theta_{1}+\theta_{2}=\alpha_{0}+\left(\alpha_{1} / T\right)+\left(\alpha_{2} / T^{2}\right)
$$

Recent experimental work ${ }^{5}$ has verified that the temperature dependence of the Kerr coefficient of nitrobenzene is well represented by this quadratic equation. From Eq. 12 it can be inferred that any frequency dependence of the Kerr coefficient should also manifest itself in the frequency dependence of the relative permittivity. Measurements 10,11 show that the relative permittivity of nitrobenzene is approximately frequency independent for frequencies between 0 and $10^{9} \mathrm{~Hz}$. This suggests that the Kerr coefficient is and hence the cell constant may 
be frequency independent over the same frequency range.

For the cell constant to be truely frequency independent, it is also necessary that $l$ ' be frequency independent. The quantity $l$ ' was a constant which permitted simplication of an integral (Eq. 7) by assuming that the electric field is uniform and that the effects of any non-uniformity can be accounted for accurately by adjusting the "effective" length of the capacitor plates. It has been shown 12 , however, that the space charge density and hence the electric field distribution are frequency dependent. The "effective" length, therefore, also depends on frequency. Through careful preparation of the cell and by judicious choice of the frequency ranges used, it should be possible to reduce this effect to an acceptably small perturbation.

If this be true, it is feasible to calibrate a Kerr system at a number of discrete frequencies and use the system to measure high voltage pulses. The remainder of this section will describe efforts to experimentally verify that the cell constant of a nitrobenzene-filled Kerr cell is frequency independent over the frequency range from 0 to 20,000 $\mathrm{Hz}$.

\section{Direct Voltage Measurements}

The circuitry used is shown in Fig. 1. This approach is similar in principle to the circuit which was previously ${ }^{5}$ used to determine the cell constant of a Halowax oil-filled cell under direct voltage. The apparatus has been improved somewhat by moving the beam splitter so that the light beam is split after it emerges from the Kerr cell rather than as it comes from the laser. The improvement results because in this configuration the ratio $I / I_{m}$ can be measured directly. The primary source of attenuation of the light beam is the Kerr cell. In addition, any voltage dependent source of attenuation, e..g.,

turbulence, is also due to phenomena within the Kerr cell and so will be appropriately handled by the electronics. The light beam which was split from the primary beam can be used as a reference signal for the lock-in amplifiers and as a signal which is proportional to $I_{m}$. A second lock-in amplifier, using the same reference input, is used to detect the transmittance of the system, I. Each lock-in amplifier generates a direct voltage output whose magnitude is proportional to the root mean square value of the input voltage at the reference frequency. These direct voltages are measured using digital voltmeters. The direct voltage which is proportional to $I_{m}$ is used as the reference voltage for the digital voltmeter which measures the transmittance, $I$. This meter then displays the ratio $I / I_{m}$.

To test the linearity of the system, the electric field was removed, the analyzer was rotated and the ratio $I / I_{m}$ was recorded as a function of analyzer angle, $\theta$, in the region $+40^{\circ} \leq ⿱ \mathrm{~m}, \theta \leq-20^{\circ}$. (An analyzer angle of $+45^{\circ}$ is perpendicular to the polarizated light transmitted by 


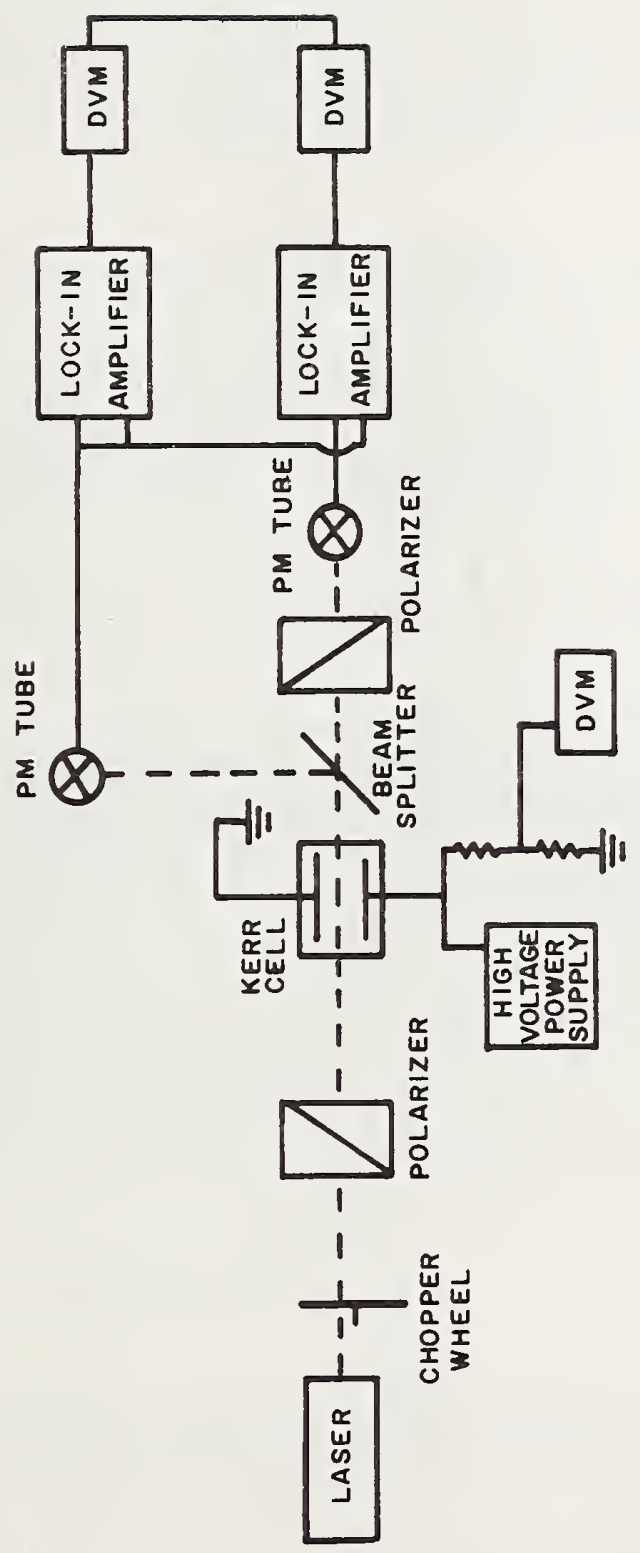


the first polarizer). Following Malthus' Law, the data were fitted to an expression of the form

$$
\left(I / I_{m}\right)_{\text {MEASURED }}=\alpha \cos ^{2} \theta
$$

For the particular apparatus used, $\alpha$ equalled 0.557 with a standard deviation of 0.088. Using this result, an estimate of the expected uncertainty in the measurement of the cell constant can be obtained. It has been shown' that

$$
\Delta V_{m} / V_{m}= \pm \Delta V / V \pm \Delta \phi / 2 \phi
$$

where $\phi$ is the phase shift between two orthogonally polarized light beams upon passage through the Kerr cell and $V$ is the applied voltage. Because the measurements are performed using direct voltage, it is anticipated that

$$
\Delta V / V \simeq 0.001<\Delta \phi / 2 \phi
$$

In these measurements, the phase shift is not measured directly. The measured quantity is the transmittance through the optical system I/I . $^{\circ}$ The relationship between the uncertainty in the measurement of the transmittance and the uncertainty in the determination of the phase shift is given by ${ }^{5}$

$\Delta \phi / \phi=\frac{\cos ^{-1}\left\{(-1)^{n}\left(I-2\left[I / I_{m} \pm \Delta I / I_{m}\right]\right)\right\}-\cos ^{-1}\left[(-1)^{n}\left(1-2 I / I_{m}\right)\right]}{n \pi+\cos ^{-1}\left[(-1)^{n}\left(I-2 I / I_{m}\right)\right]}$

In this equation, $\mathrm{n}$ is an integer defined by the relationship

$$
\phi / \pi=\mathrm{n}+\alpha,
$$

where $\alpha$ is the appropriate positive number between 0 and 1 .

Assuming $\left(1-2 I / I_{m}\right)^{2} \ll I$ and that $n \pi>\cos ^{-1}\left[(-1)^{n}\left(1-2 I / I_{m}\right)\right]$, Eq. 17 can be approximated

$$
\Delta \phi / \phi \simeq\left(2 \Delta I / I_{m}\right) / n \pi
$$




$$
\Delta V_{m} / V_{m} \simeq\left(\Delta I / I_{m}\right) / n \pi
$$

Now if $\Delta I / I_{m}=0.088$ as indicated above and if $\mathrm{n}=10$, the uncertainty in the determination of the cell constant is of order $0.3 \%$, i.e.,

$$
\Delta \mathrm{V}_{\mathrm{m}} / \mathrm{V}_{\mathrm{m}}=0.003
$$

It should be emphasized that this number is an estimate of the uncertainty which should be attainable due to the measured uncertainty in the relative transmittance. This is not an estimate of the uncertainty that would characterize the final data.

To gain some insight into the relative purity of the nitrobenzene, the resistivity of the cell was measured using high direct voltage. The electro-polished stainless steel electrodes had approximate dimensions of $4 \mathrm{~cm}$ width and $12 \mathrm{~cm}$ length and an interelectrode spacing (parallel plate configuration) of $0.5 \mathrm{~cm}$. The measured value of the resistivity was $10^{10} \Omega \cdot m$ at a field strength of $40 \mathrm{kV} / \mathrm{cm}$. A photograph of the transmittance of the Kerr system at $41 \mathrm{kV} / \mathrm{cm}$ is shown in Fig. 2. It can be seen that the field is approximately uniform between the electrodes at this field strength. For the indicated applied field strength, the next dark fringe would represent an increase in the field strength of less than 10\%. To further minimize the effect of electric field non-uniformities, measurements were taken with the photodetector measuring only light from the central portion of the interelectrode region. Previous studies ${ }^{12}$ have shown that in this cell the interelectrode field distortion is a linear function of position, i.e.,

$$
\mathrm{E}=\mathrm{ax}+\mathrm{b}
$$

The field at the center, $E_{c}$, is

$$
E_{c}=a(0.5 d)+b
$$

where $\mathrm{d}$ is the interelectrode gap spacing. The applied voltage is given by

$$
\begin{aligned}
V & =\int_{0}^{d} E d x=\int_{0}^{d}(a x+b) d x \\
& =E_{c} \cdot d .
\end{aligned}
$$




\section{KERR RESPONSE UNDER HIGH DIRECT VOLTAGE}

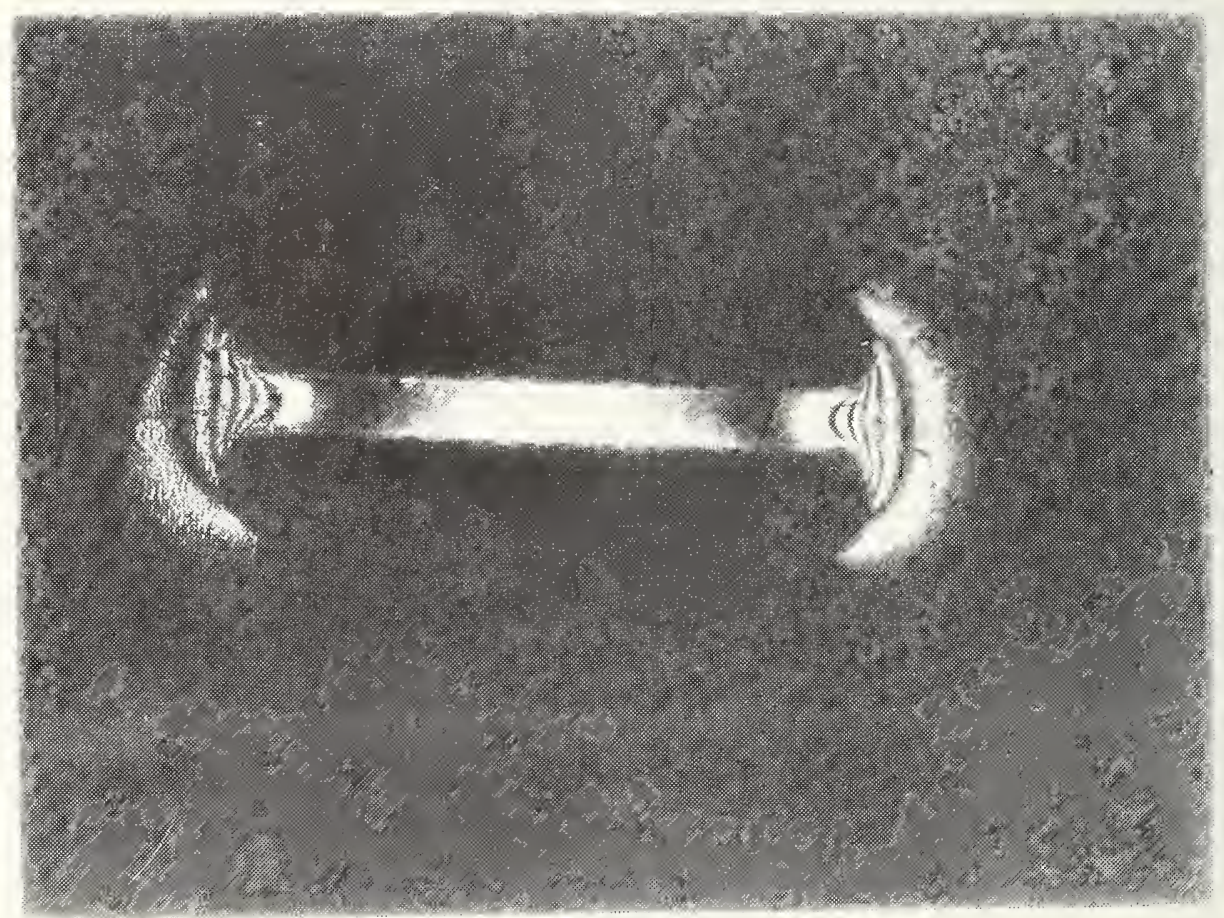

Fig. 2 Kerr response at an electric field strength of $4 \mathrm{l} \mathrm{kV} / \mathrm{cm}$. The absence of horizontal fringes indicates an approximately uniform electric field. This photograph is typical of the field distribution during the direct voltage calibration of the Kerr cell. 
The implication of the final expression is that in order to measure an electric field which is directly proportional to the applied voltage, measurements must be taken at the center of the interelectrode region. In summary, by purifying the liquid and by careful attention to electrode preparation, the non-unifonmity of the electric field ras minimized. The experimental data show that the field variation is no more than $55 \%$ of its central value. The effect of any small resicual non-uniformity was minimize $\vec{c}$ by detecting the lifgit transmitted through the center oi the interelectroce region.

Direct voltage measurements were made using the apparatus show in Fig. I. At $22.5{ }^{\circ} \mathrm{C}$ the measurea cell constant was $5820 \mathrm{~V}$ with a standard deviation of $0.2 \%(3 \sigma=0.6 \%)$. This is in good agreement with the predicted uncertainty (Eq. 21). It is estimated that the cominant systematic uncertainty in this measurement was in ine detemination o? the temperature of the oirefringent fluid--the value was not determined with any more precision than $\pm 0.5^{\circ} \mathrm{C}$. This woula contribute an uncertainty of $\pm 0.25 \%$ to the determination of the cell constant. The total uncertainty in the measurement is therefore estimated to je $\pm 0.9 \%$.

\section{Alternating Voltage Veasurements}

Measurements were taken over two different frequency ranges: 60-1000 $\mathrm{Ez}$ and 9000-20,000 $\mathrm{Hz}$. Because the results of the two sets of measurements were significantly different, each set will de äiscusseà separately.

\section{a. 60-1000 Hz Experiments}

The measurements over the range of $60 \mathrm{~Hz}$ to $1000 \mathrm{~Hz}$ were perfomed using low resistivity nitrobenzene and these results were not consistent with results taken at lower and higher lnequencies using nitrobenzene with higher resistivity. Low resistivity means that measurement problems due to electric field distortion, fluti motion anci heating will be more severe. These measurements were not included in the final determination of the cell constant but are preserted ana discusse for completeness. The resistivity of the cells used was of order $10^{\circ} \Omega \cdot m$. The Kerr response under direct voltage is shown in Fig. 3. It was found that the field was approximately uniform because the change in fieldstrength necessary to produce the next dark fringe was of order $2 \%$.

Although the cell had acceptable characteristics under direct voltage, the same was not true under alternating roltage. Fig. 4 shows the effect of fluid motion on the optical transmission of the Kerr cell. To obtain these photographs, linearly polarized light was passed through the cell, but no crossed polarizer was used. Photographs were taken at 60, 200, 770 and $912 \mathrm{~Hz}$. Under these appiled roltages, the optical transmission of the Kerr cell is no longer sufficiently well defined so as to yield usale Kerr effect data. 


\section{KERR RESPONSE UNDER HIGH DIRECT VOLTAGE.}

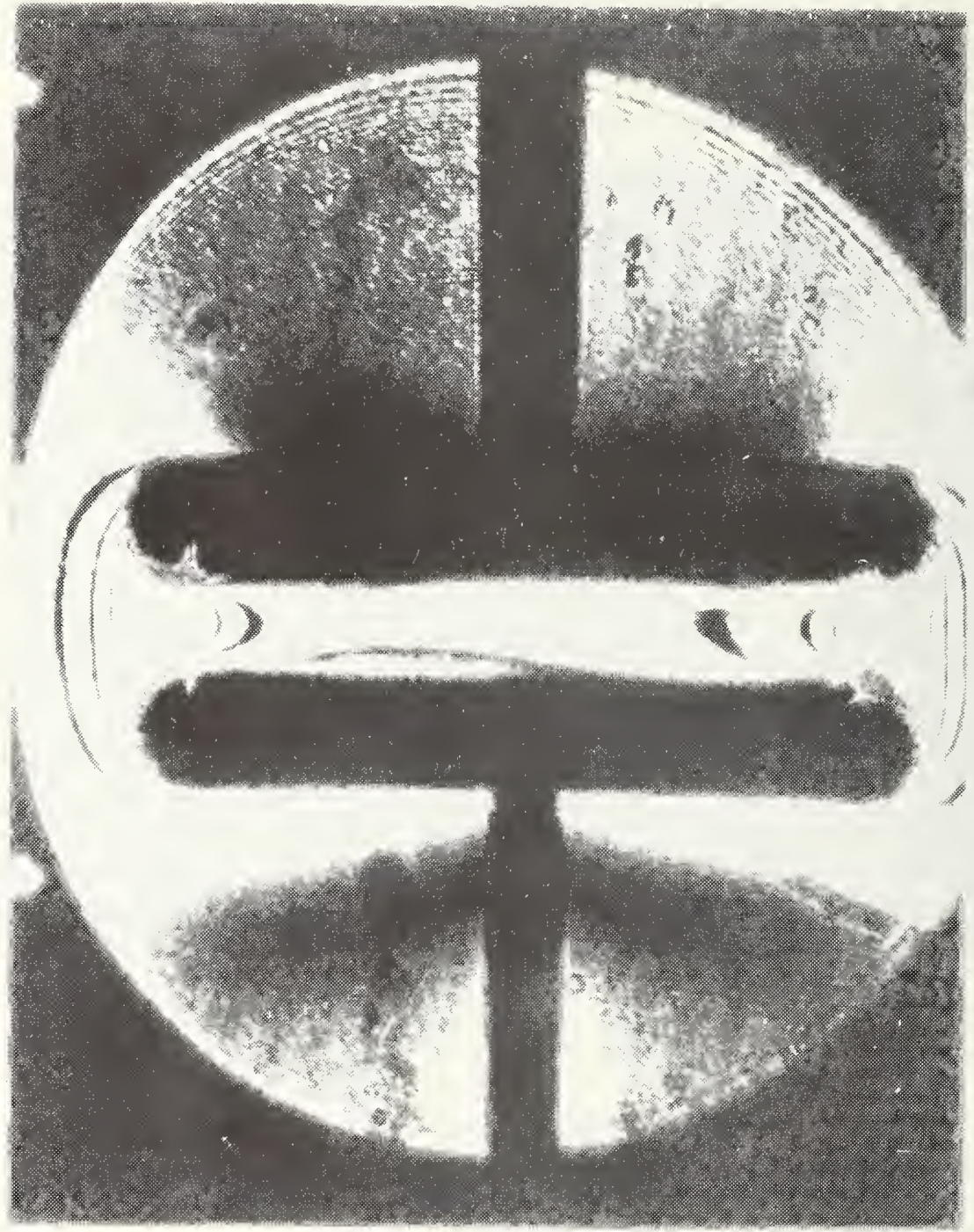

Fig. 3 The Kerr response under direct voltage in the cell that was used under alternating voltages in the frequency range 60-1000 Hz. Although the field is uniform (non-uniformity of order $1 \%$ of average value), this is probably due to equal numbers of positive and negative carriers rather than an absence of space charge. 
OPTICAL TRANSMITTANIE OF KERR CELL AT SELFCTED FREQUENCIE

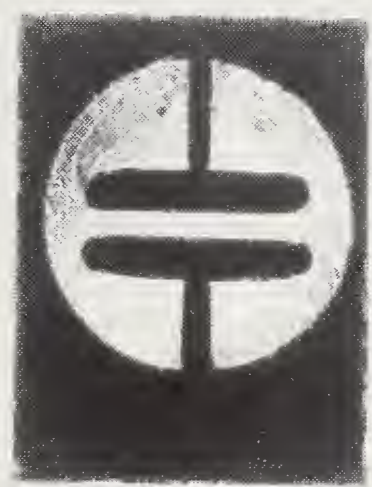

$60 \mathrm{~Hz}$

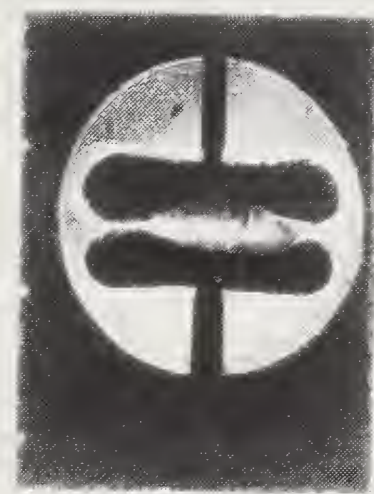

$770 \mathrm{~Hz}$

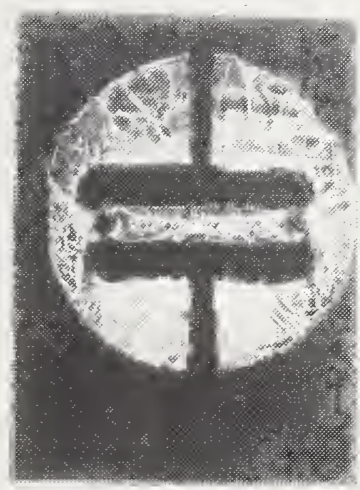

$200 \mathrm{~Hz}$

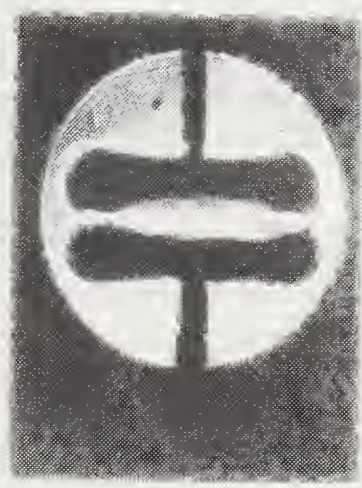

$912 \mathrm{~Hz}$

Fig. 4 The transmittance of the cell is influenced by the frequency of the applied voltage. All of these photos were taken at the same field strength, nominally $12 \mathrm{kV} / \mathrm{cm}$. 
To obtain additional information concerning the behavior of the nitrobenzene under these conditions, the resistance of the cell was measured. Under direct voltage the resistance was calculated from the measured voltage and current. Under alternating voltage the measurement process was somewhat more complicated.

The Kerr cell can be represented as a capacitor, $\mathrm{C}_{\mathrm{K}}$, in parailel with a resistor, $R_{K}$. To determine $R_{K}$, a resistor $R$ and capacitor $C$ are connected in parallel with each other and the combination in series with the Kerr cell between the Kerr cell and ground. A two-phase voltmeter was used to measure both the in-phase and quadrature components of the voltage developed across $\mathrm{R}$ and $\mathrm{C}$ when a high voltage signal was applied to the Kerr cell. The low voltage capacitor, C, was a variable capacitor and at each frequency its value was chosen so that the quadrature component as measured by the two-phase voltmeter was zero. When the quadrature component is zero,

$$
\mathrm{R}_{\mathrm{K}} \mathrm{C}_{\mathrm{K}}=\mathrm{RC}
$$

The value of $R$ was measured to be $1008 \Omega$ and assumed to be frequency independent to within the sensitivity of this experiment. Similarly, $C$ and the capacitance of the Kerr cell were measured at low voltage and $1000 \mathrm{~Hz}$. The capacitance of the Kerr cell had measured value, $\mathrm{C}_{\mathrm{K}}=99.7 \mathrm{pF}$. This value was assumed to be independent of both frequency and voltage. Using these values the resistance of the Kerr cell at various frequencies was obtained and are listed in Table 1.

Table 1. Resistance of the Kerr Cell as a Function of the Frequency of the Applied High Voltage.

$\begin{array}{rl}\text { Frequency }(\mathrm{Hz}) & \mathrm{R}_{\mathrm{K}}(\Omega) \\ 0 & 8.6 \times 10^{8} \\ 46 & 3.9 \times 10^{7} \\ 100 & 3.9 \times 10^{7} \\ 199 & 3.7 \times 10^{7} \\ 455 & 3.3 \times 10^{7}\end{array}$

Although insufficient data were taken to permit an unambiguous interpretation of the fluid behavior, a model which invokes particulate carriers is consistent with the observed behavior. Under direct voltage the particulate carriers shuttle charges back and forth between the electrodes. Because of the relatively large number of carriers the 
net charge density as determined by the Kerr effect will be small while the number of positive and negative carriers is large. Therefore under direct voltage, low resistivity with very small space charge distortion is observed.

There is also a conditioning effect under direct voltage which can be explained by assuming that the particulate carriers become trapped on the electrode surfaces. As the number of carriers is decreased, the current at a given voltage decreases so the resistivity increases.

Under alternating voltage, however, no trapping would occur so the measured resistivity would be lower. A critical test of the adequacy of this model is that at some frequency the particulate carriers should not be able to follow the rapidly changing voltage and the resistance should begin to increase with increasing voltage. The frequency range at which this should occur can be theoretically estimated. In a cell with plate spacing $0.5 \mathrm{~cm}$ and at a voltage level of 30,000 volts, the time required for charge carrier to traverse from one electrode to the other is of order $8 \times 10^{-3} \mathrm{~s}, 13,14$ If the carrier is to have an insignificant effect on the conduction process, this time should be very long compared to one half of the period of the applied voltage. This condition is satisfied when the frequency is of order $1000 \mathrm{~Hz}$. Although this calculation is very approximate, it does augur well for successful operation of the Kerr cell at higher frequencies.

\section{b. Measurements at $\dot{9}, 000-20,000 \mathrm{~Hz}$}

To obtain a higher frequency, a series-resonant high voltage system was constructed. Three air core solenoids were wound. Each solenoid was about $57 \mathrm{~cm}$ long and had approximately three hundred turns of \#l8 wire. Each inductor had an inductance of about $0.01 \mathrm{~h}$ and could carry about 10 amps continuously with only convective cooling. One of the inductors was tapped so that a number of inductance values could be obtained. The voltage and current source was a commercially available power amplifier having an output rating of $3 \mathrm{kVA}$. Half-power points were at about $40 \mathrm{~Hz}$ and $20,000 \mathrm{~Hz}$. The total resonant circuit including the Kerr cell had a $Q$ of about 100. To insure that the applied voltage signal was a sine wave, as would be predicted by the circuit parameters, an attempt was made to measure the harmonic distortion at a resonant frequency. The wave analyzer used could resolve any component which was as large as $0.01 \%$ of the fundamental. No harmonics could be detected. The frequency of the applied voltage and the measured cell constant at each frequency are shown in Table 2 .

Each of the values of the cell constant listed is the average of measurements made during at least 8 different half-cycles of the applied voltage waveform and taken at at least 4 different voltage levels. The cell temperature was maintained at $24^{\circ} \mathrm{C}$ during these measurements. 
Table 2. Measured cell constants over the frequency range of 9,000-20,000 Hz.

\begin{tabular}{cc}
$\begin{array}{c}\text { Frequency } \\
\text { (Hz) }\end{array}$ & $\begin{array}{c}\text { Cell Constant } \\
\text { (volts) }\end{array}$ \\
\cline { 1 - 1 } 9,110 & 5920 \\
10,740 & 5890 \\
11,420 & 5910 \\
12,500 & 5870 \\
12,610 & 5870 \\
13,350 & 5900 \\
16,650 & 5920 \\
17,610 & 5910 \\
18,790 & 5920 \\
19,220 & 5900
\end{tabular}

Each determination of the cell constant was made at the peak of a selected half-cycle of the applied sinusoidal high voltage. At each voltage level, an equal number of measurements were made at positive and negative half-cycles. To within the sensitivity of the experiment, no polarity dependence was detected.

The applied high voltage was measured using a capacitor divider and a digital voltmeter. The high voltage element in the capacitor divider was a three-terminal compressed-gas capacitor with a capacitance value of $104.5 \mathrm{pF}$. The low voltage component was a polystyrene capacitor having a capacitance of $1.040 \mu \mathrm{F}$. The divider ratio was therefore 9952:1. The scale of the digital voltmeter was calibrated (by the manufacturer) to indicate the true rms value of the signal. The performance of the digital voltmeter was verified using a true rms meter which incorporated a thermal converter. Because the applied signal was a very pure sine wave, the peak value of the applied voltage could be calculated from its rms value.

\section{Pulse Measurements}

Following these measurements of the cell constant, without use of a pulse divider, the cell was calibrated under pulsed voltage with respect to a voltage divider. The voltage generating-measuring system was the system described earlier which consisted of a generator capable of producing an approximately rectangular pulse, with rise and fall times of about $I$ Hs and a duration of about $10 \mu \mathrm{s}$, and a $500 \Omega$ resistor 
divider. The low voltage output of the divider was measured using an oscilloscope operated in a suppressed zero mode. The measured value of the cell constant was $5840 \mathrm{~V}$ at temperature of $22.5^{\circ} \mathrm{C}$. To compare this value with the value determined under low frequency alternating voltage at $24^{\circ} \mathrm{C}$, it is necessary to correct for temperature. It has been previously shown ${ }^{5}$ that, to within the limits of measurement accuracy,

$$
\frac{I}{V_{m}} \frac{\partial V_{m}}{\partial T}=-\frac{1}{2 B} \frac{\partial B}{\partial T}
$$

i.e., the temperature dependence of the cell constant is determined by the temperature dependence of the Kerr coefficient. From Eq. 6,

$$
\mathrm{V}_{\mathrm{m}, \mathrm{T}_{1}}=\left(\frac{\mathrm{B}_{2}}{\mathrm{~B}_{\mathrm{T}_{1}}}\right) \mathrm{V}_{\mathrm{m}, \mathrm{T}_{2}} \text {, }
$$

where the subscripts $\mathrm{T}_{1}$ and $\mathrm{T}_{2}$ correspond to two different temperatures. Combining Eqs. 12 and 13,

$$
B=A_{0}+\left(A_{1} / T\right)+\left(A_{2} / T^{2}\right)
$$

The best available values for the coefficients are ${ }^{5}$

$$
\begin{aligned}
& A_{0}=2.546 \times 10^{-11} \mathrm{mV}^{-2} \\
& A_{1}=-1.717 \times 10^{-8} \mathrm{~K} \mathrm{mV}^{-2} \\
& A_{2}=3.136 \times 10^{-6} \mathrm{~K}^{2} \mathrm{mV}^{-2} .
\end{aligned}
$$

Using these values in $\mathrm{Eq}$. 28, if the value of $\mathrm{V}_{\mathrm{m}}$ at $22.5^{\circ} \mathrm{C}$ is $5840 \mathrm{~V}$, the value at $24^{\circ} \mathrm{C}$ is $5900 \mathrm{~V}$.

Fig. 5 shows graphically the fluctuation of the measured value of the cell constant under the various high voltage waveforms that were 


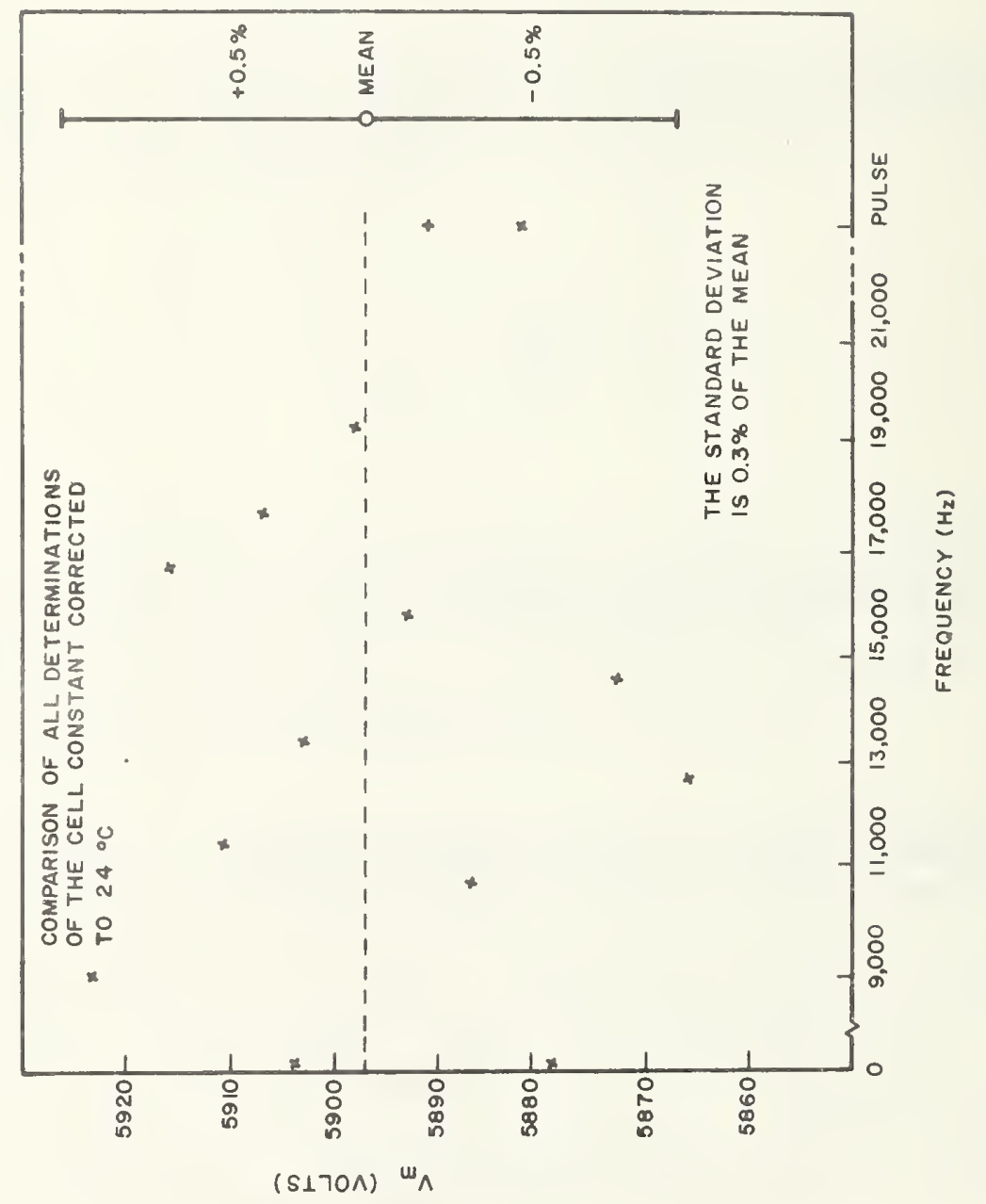

0
0
4
01
0
$4-1$
01
5
60
3
3
$6-1$
0

11

ఠে

\&

灾

검

है।

$\stackrel{0}{+}$

4

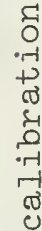

采

4

ธำ

.

สี

봉

తే

n

क्ष 
applied. The significance of these measurements is that they indicate that a Kerr system can indeed be calibrated at direct or low frequency alternating voltage and then be used to calibrate a pulse measurement system at operating voltage levels. This approach then provides simultaneous, in situ, calibration of the divider ratio and the measuring device, i.e., the sum of the two tems on the right side of Eq. 2 . 
The author would like to acknowledge the contributions of E. C. Cassidy, J. E. Jones, R. J. Sojka, and M. Zahn, all of whom participated in the experimental work which served as the basis for the appendices of this report. In addition, it should be noted that W. A. Bagley provided technical support during all of the experiments described. Finally the author would like to thank M. Misakian for his careful reading of and comments on the manuscript and J. E. Cunnjingham and E. D. Sims for their assistance in the preparation of the manuscript. 
References

1). T. Harada, et al., "Development of a High Voltage Universal Divider" Paper No. F 75 560-3 IEED Power Engineering Society Summer Meeting, San Francisco, Calif., July 20-25, 1975.

2). Intemational Electrotechnical Commission, High-Voltage Test Techniaues, IEC Publication 60, pp. 51-91, (Bureau Central de la Commission Electrotechnique Internationale, I, rue de Varembe, Genève, Swisse) 1962.

3). J. H. Park and H. N. Cones, "Sphere-Gap Volt-Time Curves-Reference Standards for Steep Front Measurements" AIEE Conference Paper, Reprint No. 57-215, 1957.

4). E. Kuffel and M. Abdullah, "High Voltage Engineering" Pergammon Press, New York, p. 273, 1970.

5). R. E. Hebner, E. C. Cassidy, R. J. Sojka, "Development and Analysis of Techniques for Calibration of Kerr Cell Pulse-Voltage Measuring Systems VIII" NBSIR 74-564, Aug. 1974.

6). E. C. Cassidy, H. N. Cones, D. C. Wunsch and S. R. Booker, "Calibration of a Kerr Cell System for High-Voltage Pulse Measurements" IEEE Trans. Instru. Meas., Vol. IM-I7, pp. 313-320, 1968.

7). E. C. Cassidy, W. E. Anderson and S. R. Booker, "Recent Refinements and Developments in Kerr System Electrical Measurement Techniques", Vol. IM-21, pp. 504-510, 1972.

8). U. Krüger, R. Pepperl, and U. J. Schmidt, "Ilectrooptic Naterials for Digital Light Beam Deflectors" Proc. IEEE, Vol. 61, pp. 992-1007, 1973.

9). C. G. Le Fevre and R.J.W. Le Ferre, "The Kerr Effect. Its Measurement and Applications in Chenistry" Rev. Pure Appl. Chem., Vol. 5, pp. 261-318, 1955.

10). A. von Hippel, "Tables of Dielectric Materials Volume IV" Technical Report No. 57, Laboratory for Insulation Research, Massachusetts Institute of Technology, 1953.

11). G. I. Clark, "Dielectric Properties of Nitrobenzene in the Region of Anomalous Dispersion" J. Chem. Phys., Vol. 25, pp. 125-129, 1956.

12). E. C. Cassidy, R. E. Hebner, M. Zahn, and R. J. Sojka, "Kerr-Eifect Studies of an Insulating Liquid Under Varied High Voltage Conditions" IEEE Trans. Elec. Insul. EI-9, pp. 43-56, 1974. 
13). M. Zahn, C. F. Tsang, and S. Pao, "Transient Electric Field and Space-Charge Behavior for Unipolar Ion Conduction" J. Appl. Phys., Vol. 45, pp. 2432-2440, 1974.

14). E. J. Hopfinger and J. P. Gosse, "Charge Transport by SelfGenerated Turbulence in Insulating Liquids Submitted to Unipolar Injection" Phys. Fluids, Vol. 14, pp. 1671-1682, 1971. 
Improved Techniques for the Measurement of High Voltage Impulses Using the Electro-optic Kern Elfect

The material presented in this appendix is a portion of a preprint of a talk by R. E. Hebner, $\Xi$. C. Cassidy and J. E. Jones at the 1975 Electrical and Electronic Neasurement and Test Instrument Conference, Ottawa, Canada, Nay 15, 1975. 


\section{INTRODUCTION}

Accurate measurement of high voltage pulses is important in a wide range of applications. These include pulse testing of power system equipmentl,2, the design and reliability of components used in radar systems, the design and operation of pulsed lasers 3 and the apparatus used in fusion research ${ }^{4}, 5$, and in research and development work such as exploding wire phenomena ${ }^{6}$ and nuclear effects simulation. Conventionally, these measurements are made using a spark gap and/or a measurement system that incorporates a high voltage divider.

The procedure used in spark gap measurements and a description of the resistors in the $500 \Omega$ pulse-voltage divider used in this work have been published. 7 Descriptions of the performance, reliability, useful range, and errors characteristic of various types of dividers are available.8-16 A characteristic common to these systems is that the waveform is obtained by photographing the oscilloscope deflection produced by the voltage across the low voltage arm of the divider. The peak value is obtained either from a photograph as above, or through the use of a peak reading voltmeter.

In recent years, an alternative approach to pulse voltage measurement, based on the electro-optic Kerr effect, has been developed.17-21 The precision and accuracy of the method have been demonstrated. A disadvantage of this technique that has been identified 22 is that the non-linear relationship between the Kerr system transmittance and the applied voltage makes the data from the Kerr system difficult to interpret. This paper describes a system which minimizes that difficulty.

The system uses a transient recorder to digitize and store the Kerr response. Digitizing the Kerr response offers two advantages over digitizing the low side voltage of the divider directly. The first is the inherent advantage of optical coupling--protection of the sensitive electrical apparatus from high voltage or high current surges. Second, the nonlinearity of the Kerr response may provide a more accurate measurement of much of the voltage waveform than would digitizing the low voltage signal obtained from a very accurate divider. The improved accuracy can result because the measurement uncertainty introduced by the digitizer contributes directly to the uncertainty in voltage measurement when a divider is used, but only indirectly when the measurement is made using a Kerr system.

The digitized Kerr response is a series of numerals representing the value of the transmittance of the Kerr system at preselected instants during the high voltage pulse. Using a computer, the voltage as a function of time can be calculated.

\section{THEORY}

If an electric field is applied to a substance the difference between the index of refraction for light polarized parallel to the applied 
field, $\mathrm{n}_{11}$, and the index, $\mathrm{n}_{1}$, for light polarized perpendicular to the applied field is given by the expression

$$
\mathrm{n}_{11}-\mathrm{n}_{1}=\lambda B E^{2} \text {. }
$$

In Eq. I, $\lambda$ is the wavelength of the light, B is the Kerr coefficient of the material and the electric field is denoted by E. From Eq. I, it follows that upon propagation through the material the phase shift, $\phi$, between the component of the light beam polarized parallel to and the component polarized perpendicular to the applied field is given by

$$
\phi=2 \pi \int_{0}^{L} B E^{2} d l \text {. }
$$

In Eq. 2, I is the length of the optical path through the applied field.

In the most basic arrangement of a Kerr pulse-voltage measurement system--the arrangement used in all work presented here--light polarized at an angle of $45^{\circ}$ to the direction of the applied field passes through the Kerr cell and then impinges upon an analyzer oriented perpendicular to the original direction of polarization. Under these conditions the transmittance through the optical system is described by the relationship 23

$$
I / I_{m}=\sin ^{2}[\phi / 2]
$$

where $I$ is the instantaneous value of the transmitted light and $I_{m}$ denotes the maximum amount of transmitted light.

The Kerr systems used here for voltage measurement were parallel-plate capacitors. Using this geometry, it is assumed ${ }^{4}$ that Eq. 2 can be rewritten,

$$
\phi=2 \pi B V^{2} l \cdot / d^{2},
$$

where any modification of the phase shift due to non-uniformity in the electric field is included in the effective plate length, $\ell$ '. Defining

$$
v_{m}=d\left(2 B \ell^{\prime}\right)^{-1 / 2} \text {, }
$$

Eq. 3 can be rewritten

$$
I / I_{m}=\sin ^{2}\left[\pi\left(V / V_{m}\right)^{2} / 2\right]
$$

Eq. 6 serves as the basis for operation of a device for measuring high voltage impulses based on the electro-optic Kerr effect. The quantity $\mathrm{V}_{\mathrm{m}}$--which is the lowest voltage necessary to cause a transmission maximum in the system--is called the cell constant. The cell constant 
depends only on cell geometry and on the properties of the birefringent fluid used in the cell. For the work discussed here, the birefringent fluid was nitrobenzene which has a Kerr coefficient, B, of $3.24 \times 10^{-12} \mathrm{~m} / \mathrm{V}^{2}$ at a temperature of $296 \mathrm{~K}$ and a wavelength of $632.8 \mathrm{~nm}$. In most cases, $V_{m}$ cannot be determined to sufficient accuracy from Eq. 5 because of uncertainties in the geometrical measurements. The presently accepted calibration procedure consists of applying a voltage pulse of known magnitude to the Kerr cell and determining $V_{m}$ from Eq. 6. Once the cell constant is known, Eq. 6 is then used to determine the magnitude of other pulses.

To evaluate the uncertainty in a voltage measurement, it is convenient to recognize that from Eqs. 6 and 3, we obtain

$$
V=(\phi / \pi)^{1 / 2} V_{m}
$$

So the voltage measurement uncertainty can be expressed

$$
\Delta V / V= \pm(\Delta \phi / 2 \phi) \pm\left(\Delta V_{m} / V_{m}\right)
$$

Eq. 7 expresses the fact that the uncertainty in the voltage measurement is the sum of the uncertainty in the measurement of the Kerr system response and the uncertainty in the Kerr system calibration. The value of $\Delta \phi / \phi$ is somewhat difficult to express because the phase shift is not directly measured. The relationship between the phase shift and the transmittance, which is measured, is given by Eq. 3. This equation can be used to obtain,

$$
\Delta \phi / \phi=\frac{\cos ^{-1}\left\{(-I)^{N}\left(I-2\left[\left(I / I_{m}\right) \pm\left(\Delta I / I_{m}\right)\right]\right)\right\}-\cos ^{-1}\left[(-I)^{N}\left(I-2\left(I / I_{m}\right)\right)\right]}{N \pi+\cos ^{-1}\left[(-I)^{N}\left(I-2\left(I / I_{m}\right)\right)\right]}
$$

In Eq. 8, $\mathbb{N}$ is an integer defined by the relationship:

$$
\phi / \pi=\mathrm{N}+\alpha
$$

where $\alpha$ is the appropriate positive number between 0 and 1.

The second term in Eq. 7, the uncertainty in the calibration of the Kerr cell, has been the focus of much of the previous work in the use of the Kerr system for high voltage pulse measurement.18,19 The estimated value for this uncertainty is

$$
\Delta \mathrm{V}_{\mathrm{m}} / \mathrm{V}_{\mathrm{m}}=0.01
$$

because present Kerr systems must be calibrated by reference to a resistor divider under pulsed high voltage. 


\section{COMPUTER RECONSTRUCTION OF VOLTAGE WAVEFORM}

Previous work has demonstrated that the following procedure is sufficient to determine the pulse shape. 20 First a photograph, using a streak camera, is made of the interelectrode field. This is read, using a microdensitometer to determine the values of $I / I_{m}$ at selected times during the voltage pulse. Finally, these values are inserted in Eq. 6 and the voltage as a function of time is calculated.

The work described here removes the photograph from the above process to obtain immediate information concerning the pulse shape. The operational procedure using this approach is to detect the light transmitted through the Kerr system with a photomultiplier. The output from the photodetector is digitized and digital information concerning the transmittance as a function of time is stored in computer memory. The computer can then reconstruct the voltage waveform, i.e., determine the voltage as a function of time, using Eq. 6. The software concept is to use a main program to control eight subroutines as shown in Fig. 1. An insight into the use of the Kerr effect for voltage measurement and into the care that must be taken in computer analysis of data from Kerr systems can be obtained from a study of the operation of each of the subroutines.

The conversion subroutine is a software package made necessary by the pecularities of the digitizer and computer interface that are used.

The smoothing subroutine fits the digitized data, five data points at a time, to a third order polynomial. This routine minimizes variations in the data due to electrical noise, non-linear responses of individual channels in the digitizer or other sources.

The normalization subroutine presents the data in a form that can be analyzed according to Eq. 6. Mathematically, each transmittance maxima must be assigned a value of $I$ and each minima a value of 0 . In practice, the measured value of the transmittance at each maximum or minimum varies slightly from extremum to extremum. This variation can be due to the bandwidth of the detection system, to slight, short term variations in the laser output, to variations in the transmittance of the Kerr cell, or to digitizing errors. These variations are typically no greater than a few percent of the total difference between a minimum and a maximum. The normalization routine then sets each maximum to $l$ and each minimum to zero and the intermediate points are adjusted so that they retain the same relative spacing as before normalization. This requires a slightly different normalizing factor between each maximum and minimum.

The search and the search parameter subroutines identify the addresses of the minima and the maxima. The complication in identifying extrema comes during those portions of the voltage pulse when the relative transmittance is varying slowly with respect to the digitizing rate. In this case a number of addresses could correspond to an extremum. This situation is further complicated by the fact that at these addresses the signal recorded is not strictly constant but varies in a slight, but unpredictable manner. It is essential that these 
KERR ANALYSIS PROGRAM

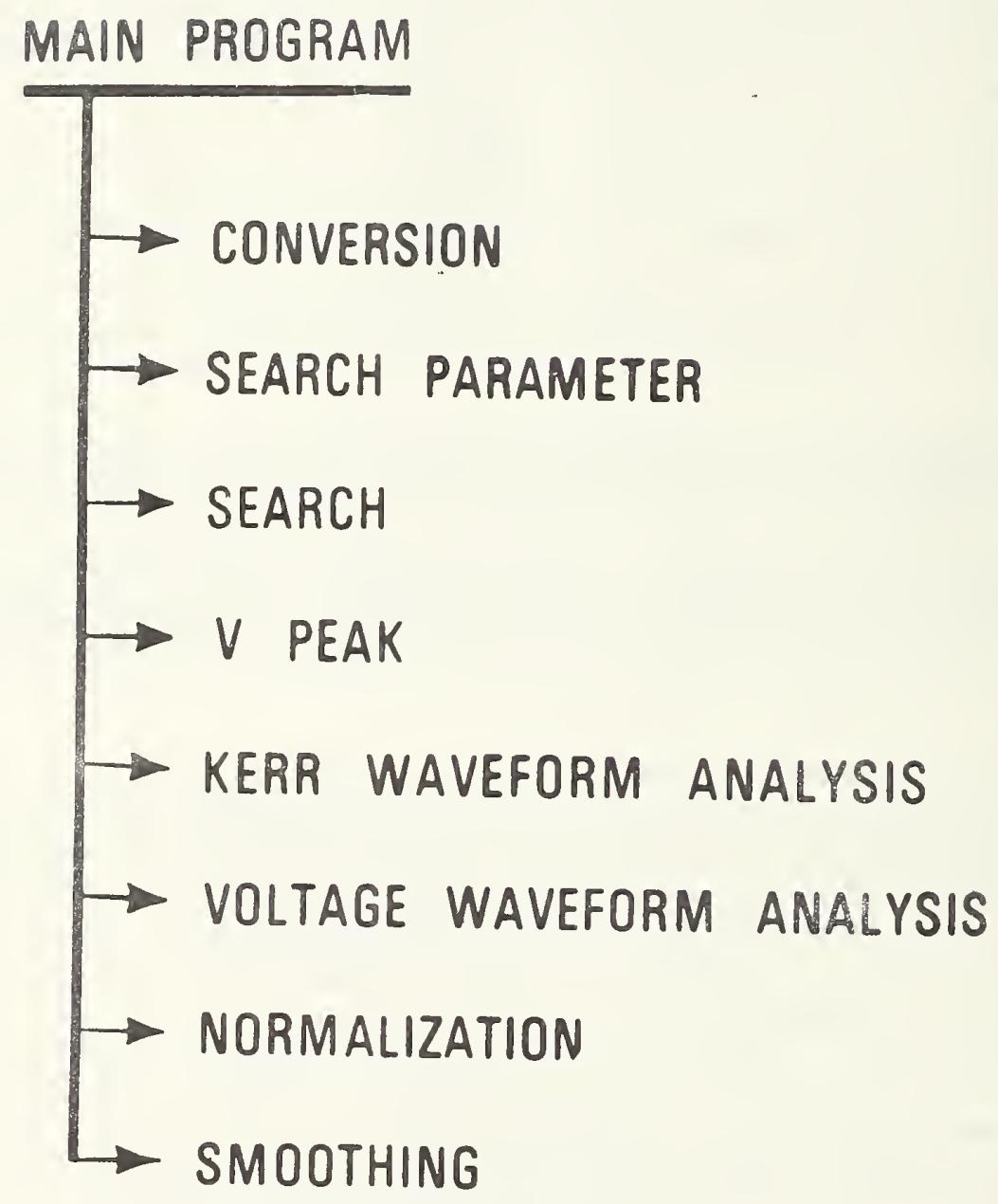

Fig. I Outline of software used to convert Kerr data into information concerning the voltage waveform. 
oscillations not be identified as extrema. The search subroutine looks both ahead of and behind a specific point to verify that a true extremum has been identified. The search parameter subroutine determines from the responses the number of data points that must be considered.

The $V$ PEAK subroutine then determines the location of the voltage peak in the Kerr response. In rare cases this point may correspond to a minimum or a maximum. In these rare cases, the normalizing subroutine handles this portion of the Kerr response correctly. It is much more likely, however, that the peak corresponds to an intermediate value of transmittance. The $V$ PEAK subroutine identifies this region and the normalization of this region of the trace uses a procedure which is somewhat different from the procedure used for the remainder of the Kerr trace.

The Kerr waveform analysis subroutine solves Eq. 6 to determine the voltage as a function of time.

The final subroutine performs voltage waveform analysis. In addition to determining the magnitude of the voltage peak and the duration of the voltage pulse (time between the points at which the voltage is $0.5 \mathrm{~V}$ peak), this subroutine calculates the virtual front time, the virtual rate of rise of the front, the virtual origin of the impulse, the virtual time to half-value and the virtual fall time. The virtual quantities are defined in the appropriate standard. I

The input parameters and the output summary for a typical voltage pulse are shown in Table 1 . The only input parameter that cannot in principle be determined by the software is the cell constant. The other four are entered to reduce computation time and to simplify the hardware and software. The Kerr trace summary gives the extrema, the location of these extrema, and the phase shift and the voltage at each point. The time between any two of the extrema can be determined by multiplying the sample interval by the difference between their location addresses. The waveform summary provides a convenient synopsis of the waveshape.

To verify the validity of the entire construction process, a photograph was taken of the pulse using a conventional divider and an oscilloscope. The pulse shape parameters determined from the reconstructed waveform and those determined from the divider-oscilloscope agreed to within the uncertainty imposed by the finite width of the oscilloscope trace. For example, from the oscillogram the pulse duration was greater than $6.35 \mu \mathrm{s}$ but less than $6.66 \mu \mathrm{s}$. From the computer reconstruction a value for the pulse duration of $6.43 \mu \mathrm{s}$ was calculated. Of course if one wishes to view the entire waveform, a reconstruction like that shown in Fig. 2 can be obtained. 

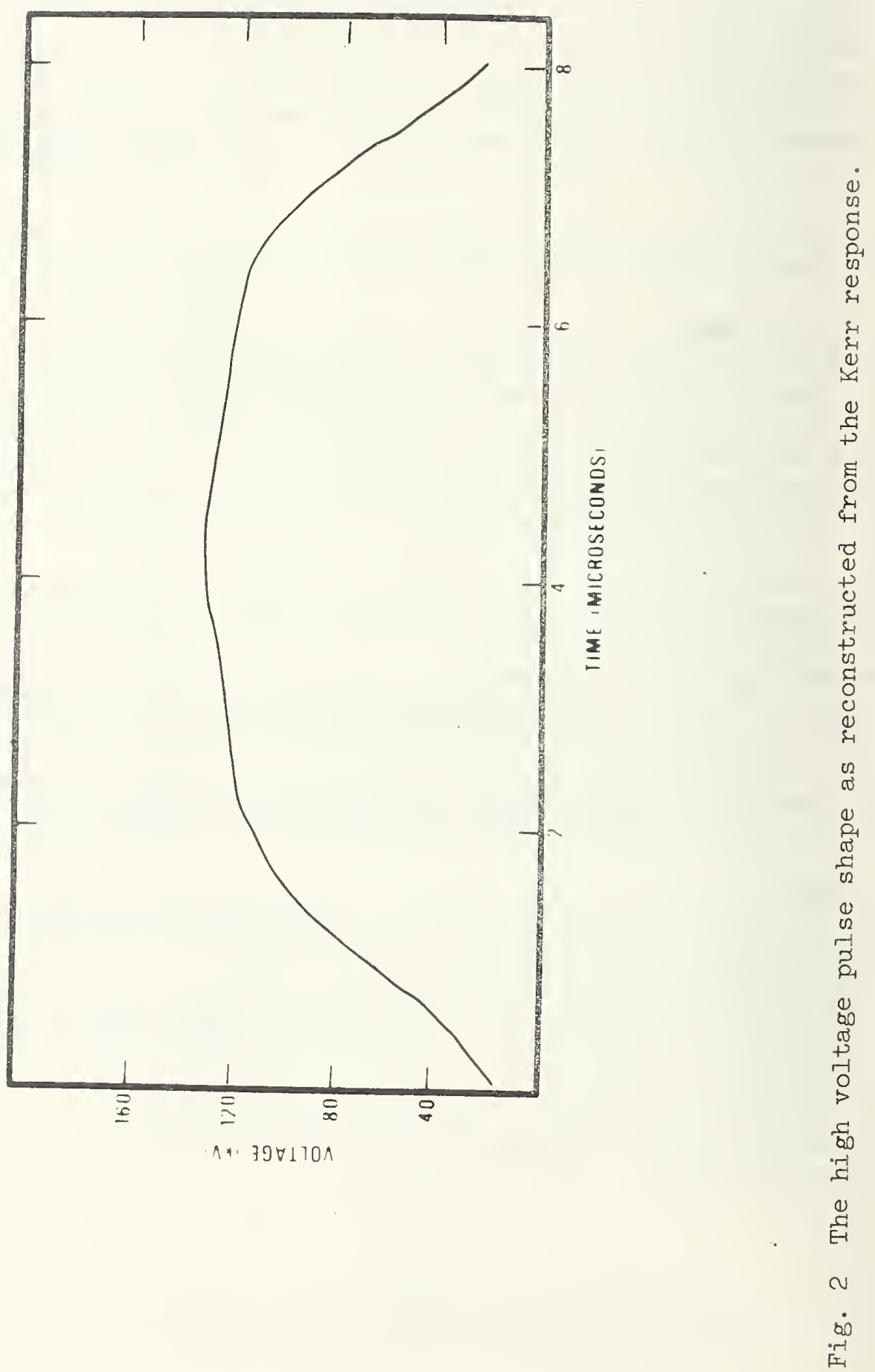


\section{REEEREITES}

I. USA anā IEEE Stanäara Iechnicues for Dielectric Tests, USAS C68.I,

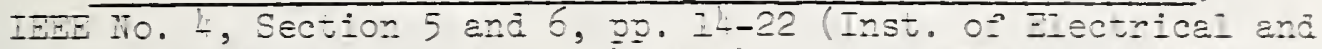
Electronic Engineers, Inc., 3L5 E. 47 Street, Ner Yonz, I.I. I00I7, JuI 19,68).

\section{International ElectrotechnicaI Comission, झ̈sh-Toltage Test}

Techniques, IEC Fujlication 60, DD. jl-91 (Bureau Central ae la Commission Electrotechnique Interrationale, I, rue de Varemoe, Genève, Swisse) I062.

3. 0. R. Wooä III, "High-Pressure Pulsec Ulecular Lasers" Froc. IEEz, พOI. 62, 2. 355-397, 1974.

4. D. E. Skelton, "The Electrical Interference Froblem in Fusion Research," Electrical Interperence in Insurumentation (IEE Conp. PuoI. iio. 65, Saroy Place, Ioncion wC2803I), 20. i-3, 1970.

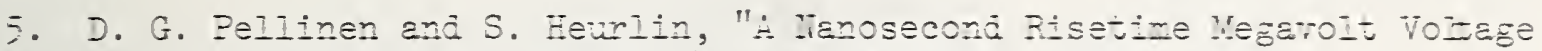
Divider," Rer. Sci. Instr., rol. L2, po. 82l-827, I9TI.

6. Z. C. Cassidy, S. H. Zimenmen, Z. Z. Tieumenn, "Zime Resolted Electrical Yeasurements in تigh Currert Discharges," Rer. Sci. Inst., VOI. 37, DD. 210-21L, 1966.

7. J. E. Parz anc F. I. Cones, "Sparz-jep Flashorer Yeasurements for Steeply Rising Voltaze Impulses," J. Res. Liat'l. Bur. Stás., roi. 6́́d, DD. 197-207, 1962 .

8. A. F. Rohtis, J. S. Kresge and $\Xi$. A. Fisher, "Tre Resporse oz Resistance Voltage Diriärs to Steep-Front Impulse Wares," iIZE Frans., vol. 76 , рart 1, פ๊. $634-646,1957$.

9. A. J. Schwab anc J.E.W. Pagel, "Precision Capacitire Toitage Diriäer for Impulse Voltage "'eesurements," IEEE Trans. on PAS, roI. PAS-9I, 이. 2376-2382, 1972 .

10. T. Harada, et al, "A Eigh Guality Voltage Divider Using Optoelectronics For Imoulse Voltage Measurements," IEEE Trens. on PAS, vol. PAS-91, 20. 494-500, Yarci/Apri1 1972.

11. M. F. Simon anç G. I. Leroy, "Contribution to a Better Unāerstanäinz o: Impuise Voltage Ueasuring Systems," IEEE Trans. Porer Lppar. Sys., rol. EAS-9I, 2D. $478-484,1972$. 
12. F. C. Creed, M.M.C. Collins, Aa. Pedersen, and P. Lausen,

"Evaluating Impulse Measurements--A New Approach," IEEE Trans. Power Appar. Sys., vol. PAS-91, pp. 485-494, 1972.

13. F. A. Fisher, "Transient Response of Impulse Voltage Dividers," AIEE Trans. Communication and Electronics, vol. 77, part 1, pp. 411-420, 1958.

14. W. Zaengl, "The Impulse Voltage Divider With Lead," Bull, d I'A.S.E., vol. 61, pp. 1003-1017, 1970.

15. N. R. Hylten-Cavallius and L. Vaughan, "Calibration and Checking Methods of Rapid High Voltage Impulse Measuring Circuits," IEEE Trans. Power Appar. Sys., vol. PAS-89, pp. 1393-1403, Sept./Oct. 1970.

16. M. M. Brady and K. G. Dedrick, "High-Voltage Pulse Measurement With A. Precision Capacitive Voltage Divider," Rev. Sci. Instr., vol. 33, pp. 1421-1428, 1962 .

17. D. C. Wunsch and A. Erteza, "Kerr Cell Measuring System for High Voltage Pulses," Rev. Sci. Instr., vol. 35, pp. 816-820, 1964.

18. E. C. Cassidy, H. N. Cones, D. C. Wunsch and S. R. Booker, "Calibration of a Kerr Cell System for High-Voltage Pulse Measurements," IEEE Trans. on Instr. and Meas., vol. IM-17, pp. 313-320, 1968.

19. E. C. Cassidy, H. N. Cones, and S. R. Booker, "Development and Evaluation of Electro-optical High-Voltage Pulse Measurement Techniques," IEEE Trans. on Instr. and Meas., vol. IM-19, pp. 395-402, 1970.

20. E. C. Cassidy, W. E. Anderson, and S. R. Booker, "Recent Refinements and Developments in Kerr System Electrical Measurement Techniques," IEEE Trans. on Instr. and Meas., vol. IM-21, pp. 504-510, 1972.

21. R. E. Hebner and S. R. Booker, "A Portable Kerr System for the Measurement of High Voltage Pulses" Proc. of 1975 IEEE SOUTHEASTCON, vol. 1, pp. 3A-1-1 through 3A-1-5, 1975.

22. A. J. Schwab, "High Voltage Measurement Techniques" MIT Press, Cambridge, p. 84, 1972 .

23. E. C. Cassidy, R. E. Hebner, M. Zahn, and R. J. Sojka, "Kerr Effect Studies of an Insulating Liquid Under Varied High-Voltage Conditions" IEEE Trans. Elec. Insul., vol. EI-9, pp. 43-56, 1974.

24. R. E. Hebner and E. C. Cassidy, "Measurement of $60 \mathrm{~Hz}$ Voltages Using the Kerr Effect" Rev. Sci. Instr., vol. 43, pp. 1839-1841, 1972. 
Table 1. Summary of the Kerr response and the waveform of the high voltage pulse. This information is calculated, and is immediately available, for each high voltage pulse.

\author{
DATE? 10 April 1975 \\ TIME? 10:49 \\ INPUT PARAMETERS \\ VOLTAGE RANGE? 1.0 \\ SAMPLE INTERVAL? $0.00000001 \mathrm{~s}$ \\ MAXIMA OBSERVED? 17 \\ MINIMA OBSERVED? 16 \\ CELL CONSTANT? 33.64
}

VOLTAGE WAVEFORM SUMMARY

MAGNITUDE OF VOLTAGE PEAK

VIRTUAL FRONT TTME

VIRTUAL RATE OF RISE OF FRONT

VIRTUAL ORIGIN OF IMPULSE

VIRTUAL TIME TO HALF VALUE

VIRTUAL FALL TIME

DURATION OF IMPULSE
$138.158 \mathrm{kV}$

$3.172999 \mathrm{E}-6 \mathrm{~S}$

$4.354164 \mathrm{E}+7 \mathrm{kV} / \mathrm{S}$

$-3.324373 \mathrm{E}-8 \mathrm{~S}$

$7.848243 \mathrm{E}-6 \mathrm{~S}$

$2.838999 \mathrm{E}-6 \mathrm{~S}$

$6.429999 \mathrm{E}-6 \mathrm{~S}$ 
KERR TRACE SUMMARY

\begin{tabular}{|c|c|c|c|c|}
\hline I & LOC & $\mathrm{N}$ & $\phi$ & VOLTAGE $(\mathrm{kV}$ \\
\hline 1 & 48 & 1 & 3.14159 & 33.64 \\
\hline 0 & 71 & 2 & 6.28319 & 47.5741 \\
\hline 1 & 88 & 3 & 9.42478 & 58.2662 \\
\hline 0 & 100 & 4 & 12.5664 & 67.28 \\
\hline 1 & 111 & 5 & 15.7080 & 75.2213 \\
\hline 0 & 123 & 6 & 18.8496 & 82.4008 \\
\hline 1 & 133 & 7 & 21.9912 & 89.0031 \\
\hline 0 & 145 & 8 & 25.1327 & 95.1483 \\
\hline 1 & 156 & 9 & 28.2743 & 100.920 \\
\hline 0 & 170 & 10 & 31.4159 & 106.379 \\
\hline 1 & 185 & 11 & 34.5575 & 111.571 \\
\hline 0 & 203 & 12 & 37.6991 & 116.532 \\
\hline 1 & 227 & 13 & 40.8407 & 121.291 \\
\hline 0 & 269 & 14 & 43.9823 & 125.869 \\
\hline 1 & 336 & 15 & 47.1239 & 130.287 \\
\hline 0 & 371 & 16 & 50.2655 & 134.560 \\
\hline .956986 & 427 & 16 & 52.9893 & 138.158 \\
\hline 0 & 486 & 16 & 50.2655 & 134.560 \\
\hline 1 & 529 & 15 & 47.1239 & 130.287 \\
\hline 0 & 598 & 14 & 43.9823 & 125.869 \\
\hline 1 & 640 & 13 & 40.8407 & 121.291 \\
\hline 0 & 659 & 12 & 37.6991 & 116.532 \\
\hline 1 & 673 & 11 & 34.5575 & 111.571 \\
\hline 0 & 685 & 10 & 31.4159 & 106.379 \\
\hline 1 & 696 & 9 & 28.2743 & 100.920 \\
\hline 0 & 707 & 8 & 25.1327 & 95.1483 \\
\hline 1 & 716 & 7 & 21.9912 & 89.0031 \\
\hline 0 & 727 & 6 & 18.8496 & 82.4008 \\
\hline 1 & 736 & 5 & 15.7080 & 75.2213 \\
\hline 0 & 748 & 4 & 12.5664 & 67.28 \\
\hline 1 & 760 & 3 & 9.42478 & 58.2662 \\
\hline 0 & .775 & 2 & 6.28319 & 47.5741 \\
\hline 1 & 794 & 1 & 3.14159 & 33.64 \\
\hline
\end{tabular}




\section{APPENDIX 2}

The paper reprinted in this appendix was published in August 1974. 


\title{
1973 Annual Report \\ Conference on \\ Electrical Insulation \\ and \\ Dielectric Phenomena
}

\author{
Prepared by the \\ CONFERENCE ON ELECTRICAL INSULATION AND \\ DIELECTRIC PHENOMENA \\ DIVISION OF ENGINEERING \\ NATIONAL RESEARCH COUNCIL
}

NATIONAL ACADEMY OF SCIENCES

WASHINGTON, D.C. 1974 


\section{Electric Field Distributions and Space Charge Behavior in Nitrobenzene under Low Frequency Alternating Voltage}

ROBERT E. HEBNER, JR. AND ESTHER C. CASSIDY National Bureau of Standards, Washington, D.C. MARKUS ZAHN AND RICHARD SOJKA University of Florida, Gainesville, Florida

\section{INTRODUC TION}

The electro-optic Kerr effect has been used by a number of workers over the last two decades to measure the electric field distribution in a variety of liquids and to study the electric field distribution around solid insulators. Measurements have typically been either under direct or pulsed high voltage.

It has long been recognized that if one wanted to use the Kerr effect to measure the electric field distribution due to the geometry of his electrodes and/or insulator forms he had two choices. Either he could perform the measurement under pulsed voltage or, alternatively, could carefully purify his liquid, coat the electrodes with an appropriate membrane and, if he confined himself to moderate field strengths, could be fairly certain that observed distortions were a result of geometry and not due to a property of the Kerr fluid itself. If uncoated electrodes or higher field strengths were used, the electric field in the Kerr liquid would be distorted. Historically, depending on the materials and their state of purity, this distortion has been attributed to chemical or electro-chemical processes either in the bulk or at the electrode surface or to the presence of suspended particles in the bulk of the field.

It was judged that an understanding of the dynamics of this distortion could lead to more accurate voltage measurement using the 
electro-optic Kerr effect and to additional understanding of electrical conductivity and breakdown phenomena in insulating liquids. We therefore measured the electric field as a function of position and time under direct and low frequency alternating voltage in a nitrobenzene-filled parallel-plate capacitor.

The data presented here were taken in a cell having nickel electrodes. The nitrobenzene was purified before it was sealed into the cell. The measured resistivity was of order $10^{8}-10^{9} \Omega-\mathrm{m}$.

\section{EXPERIMENTAL RESUL TS}

The experimental apparatus consists of a nitrobenzene-filled parallel-plate capacitor, a triggerable pulsed argon laser, crossed polarizers oriented at + and $-45^{\circ}$ to the interelectrode field direction, and appropriate photographic equipment for recording of the transmitted fringe patterns observed when the laser is flashed during high voltage operation. The laser beam is expanded and collimated to illuminate the area between and around the test cell electrodes. During direct voltage studies, the high voltage was connected to a parallel combination of the test cell and a calibrated $100 \mathrm{M} \Omega$ resistive divider. For current measurements a microammeter was placed in series with the Kerr cell between the cell and ground. For ac studies, the power-amplified output of an audio oscillator supplied a step-up transformer. The transformer's output voltage was applied to one electrode of the cell, the other electrode of the cell being grounded. The rms value of the applied voltage was measured using a 1000:1 metering tap on the transformer.

The governing equation ${ }^{1}$ for the analysis of data obtained is

$$
\left(I / I_{m}\right)_{x, t}=\sin ^{2}\left[\left(\bar{E} / \bar{E}_{m}\right)_{x, t}^{2} \pi / 2\right] .
$$

In this expression $I$ is the irradiance of the transmitted light, $I_{m}$ is the maximum irradiance, $\mathrm{E}$ is the electric field magnitude, $\mathrm{E}_{\mathrm{m}}$ is the electric field necessary to produce the first maximum in the transmitted irradiance and the overbar (e.g., in $\overline{\mathrm{A}}$ ) denotes

$$
\bar{A}=\left(L^{-1} \int_{0}^{L} A^{2} d z\right)^{1 / 2}
$$

where $\mathrm{L}$ is the geometrical length of the optical path through the applied field. It should also be noted that the subscripts $x, t$ 
indicate the time and position at which the data were taken and that we are assuming a coordinate system in which the light beam propagates in the $\mathrm{z}$-direction, and the $\mathrm{x}$-direction is perpendicular to and the $y$-direction parallel to the surfaces of the electrodes. We have analyzed data only at a specific value of $y$, the geometric center of the electrodes.

Figure 1 shows the relative electric field as a function of position under direct voltage. In order to determine the space charge density a linear fit (least squares) was performed. From the data presented the calculated space charge density ranges from $4 \times 10^{-8}$ to $14 \times 10^{-8} \mathrm{C} / \mathrm{cm}^{3}$. It is noted that the space charge density observed here agrees well with similar data obtained, using the electro-optic Kerr effect, with a chlorobiphenyl as the insulating liquid. ${ }^{2}$ In that case it was postulated "that the space charge... is due to the dissociation of the $\mathrm{H}_{2} \mathrm{O}$ molecule and consists largely of $\mathrm{H}^{+}$ions. "Even though there is good agreement in both magnitude and sign it is thought that in the present work the generation of the space charge is dominated by electrode surface rather than fluid bulk phenomena. This conclusion is based on the behavior under low frequency alternating voltage which will be discussed later in the paper.

Three trends were identified from this and similar data. First, the net charge was always positive and uniformly distributed in the bulk. Second, the space charge density decreased as the voltage level was increased, and, third, the net charge in the liquid was slightly greater when negative high voltages were applied.

The situation was radically different, however, when alternating voltage was applied. In Figure 2 is plotted the relative electric field strength as a function of distance from the high voltage electrode at various instants during the cycle of a $20 \mathrm{kV} \mathrm{rms}, 60 \mathrm{~Hz}$ applied voltage waveform (plate spacing $0.5 \mathrm{~cm}$ ). These data were taken by synchronizing a pulsed laser (light pulse width $\simeq 6 \mu \mathrm{sec}$ ) with the applied voltage waveform so that the electric field distribution was strobed at a preselected, adjustable time during the cycle. It can be seen from Figure 2 that as one progresses through one cycle of the applied voltage (of period T) a field distribution indicative of homocharge is first produced. ${ }^{3}$ Soon after the peak of the positive half-cycle the field becomes uniform. The field distribution then inverts and assumes a distribution characteristic of heterocharge. Figure 3 shows similar observations in the same cell made at selected instants during the cycle of $16 \mathrm{kV} \mathrm{rms}$ applied voltage at 60 and $120 \mathrm{~Hz}$. In contrast with the previous figure, 


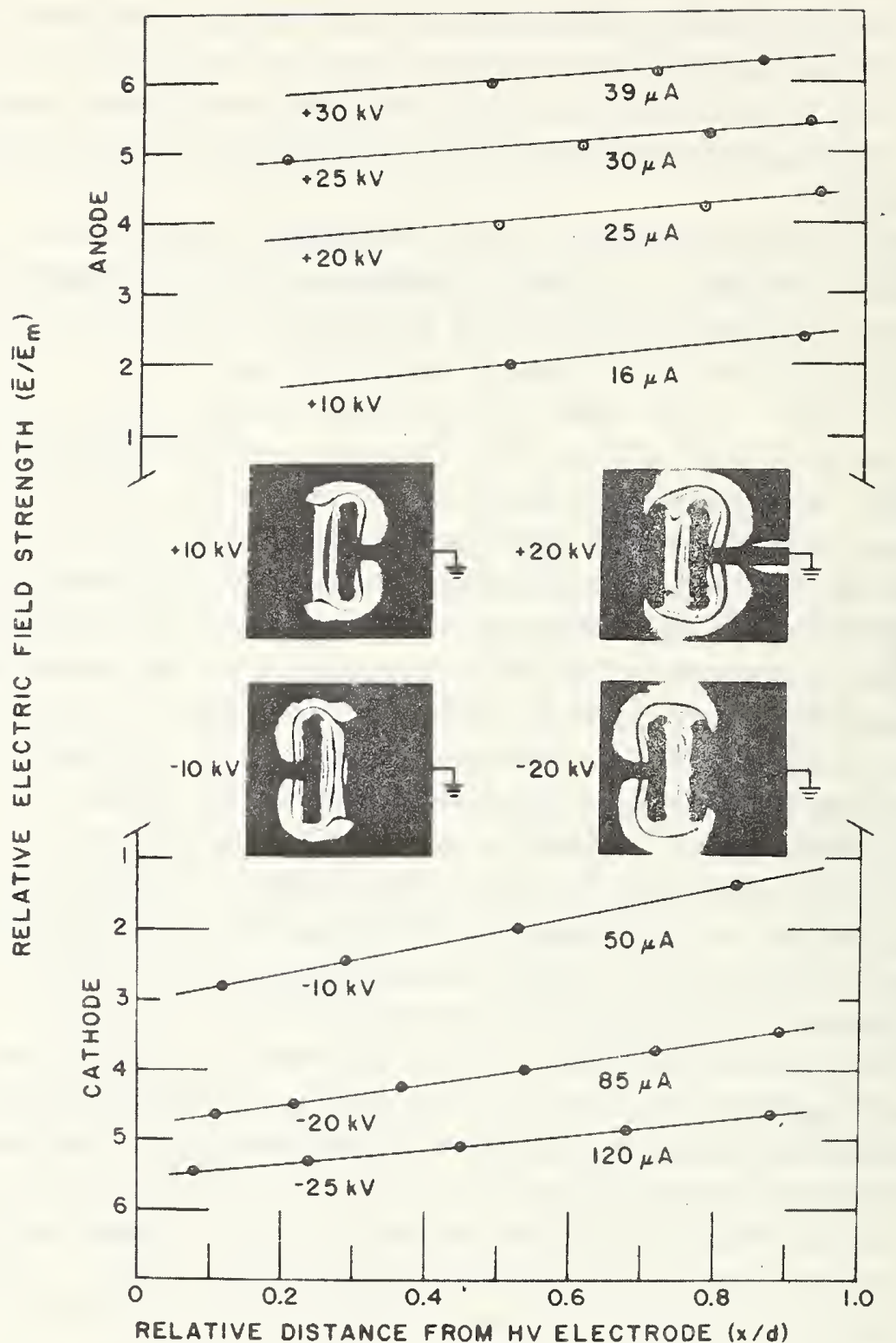

FIGURE 1 Typical field distribution data under direct voltage. Photographs from which some of the data were taken are presented in the center of the figure.

there is no longer evidence of an electric field distribution attributable to heterocharge. Note that in this context the words heterocharge and homocharge are used only to describe the relationship between the polarity of the electrode and the net charge near it. They do not imply any mechanism of charge production of transport. 
It was also observed in this work that the electric field distortion was approximately constant in the range from 60 to $120 \mathrm{~Hz}$, with measurements being performed at $60,80,100$, and $120 \mathrm{~Hz}$. At higher and lower frequencies there was a trend toward reduction in the curvature in the distributions with limiting cases being a uniform field under short pulse conditions and a field which is approximately a linear function of position under direct voltage.

\section{DISCUSSION}

There is qualitative agreement between the data and the assumption that there are particulate impurities in the system. If particulate impurities are present they are charged upon contacting an electrode. Once it leaves the initial electrode, the charge on any particle can decay due to fluid ohmic conditions. The critical parameter is the ratio of the electrical relaxation time, $\varepsilon / \sigma$, where $\varepsilon$ is the fluid permittivity and $\sigma$ its conductivity, to the transport time $d / U$, where $\mathrm{d}$ is the electrode spacing and $\mathrm{U}$ is the average particle velocity. The ratio of these times is called the electric Reynolds number ${ }^{4}$

$$
R_{e}=(\varepsilon / \sigma) /(d / U)
$$

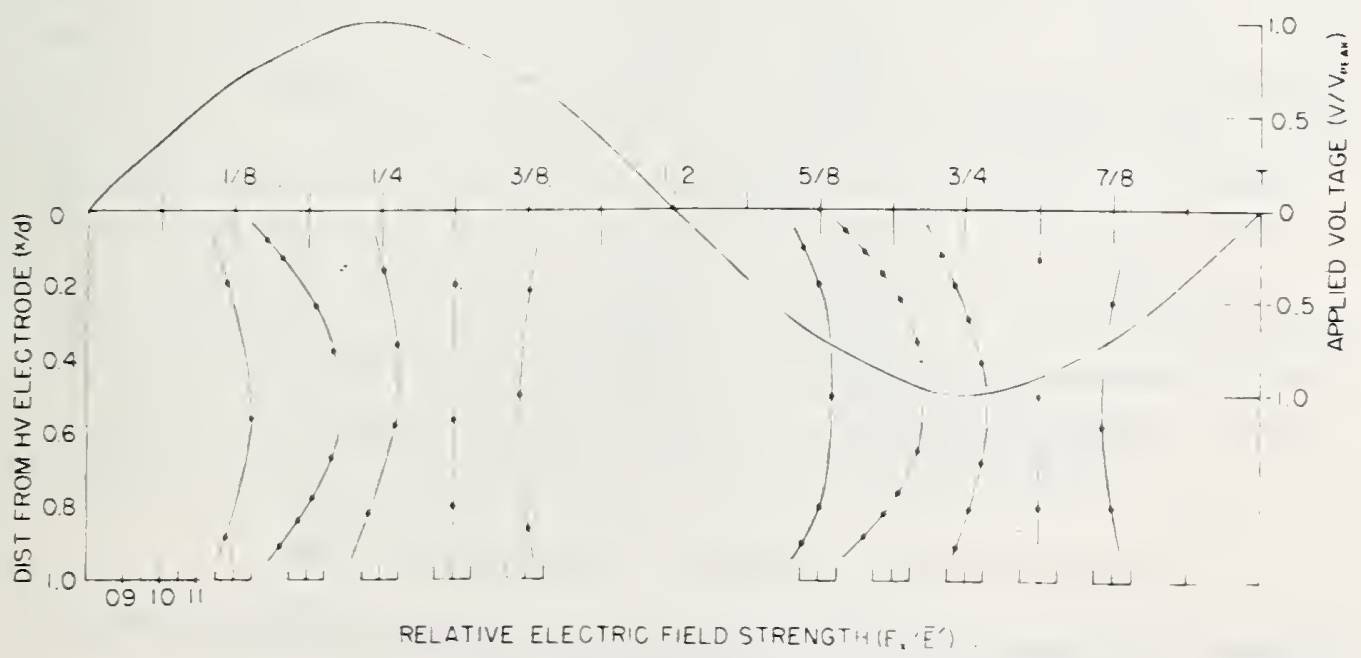

FIGURE 2 The electric field distribution at various times during the cycle of $60 \mathrm{~Hz}, 20 \mathrm{kV} \mathrm{rms}$, applied voltage. $\overline{\mathrm{E}}^{\prime}$ is the average value of the field at each instant. 

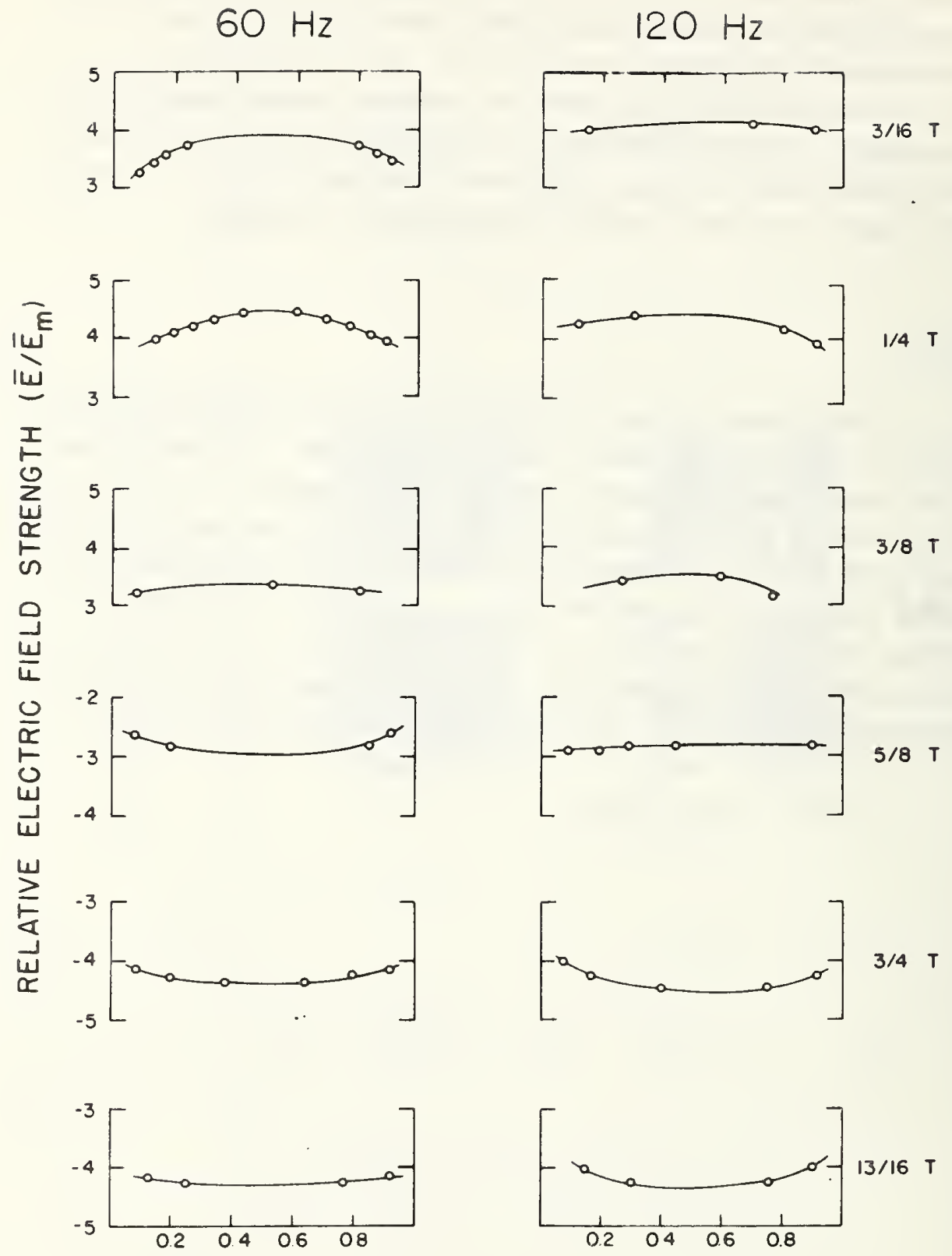

RELATIVE DISTANCE FROM HV ELECTRCDE $(x / d)$

FIGURE 3 The electric field distributions at corresponding times

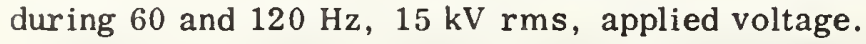

If $R_{e} \sim 1$, the net charge distribution is the sum of two expontial distributions. The predicted result is negative charge near the 
cathode and positive charge near the anode. This is observed experimentally in almost all cases. The deviations from this behavior, shown in Figure 2, may be attributable to the voltage dependence of $R_{e}$.

If $R_{e} \gg 1$, the observed behavior can be understood in terms of the roll cell model used by Felici ${ }^{5}$ and Thomas. ${ }^{6}$ This model assumes that the charge carriers move with the fluid, from electrode to electrode, with a velocity $U$. The charge on each carrier is proportional to the electric field strength at the electrode at the time that the carrier is in contact with it. This predicts that as the voltage is increasing in magnitude there will be positive charge near the positive electrode and negative charge near the negative electrode. Sometime after the peak the field should become uniform. As the field strength returns toward zero a heterocharge distribution is predicted. The reason that this heterocharge distribution was not observed in Figure 3 may be that there was insufficient sensitivity at the low voltages.

\section{CONCLUSIONS}

It has been shown that the electric field distribution and, consequently, the space charge distribution, in a liquid insulant are different under direct and. low frequency alternating voltage and that both differ from ideal distribution predictable from geometry. It has been recently shown that in commercial insulating liquids the breakdown is controlled by space charge. 2 For lack of more substantial information, however, authors ${ }^{7}$ have obtained the breakdown field strength at $60 \mathrm{~Hz}$ in an insulating liquid by measuring the breakdown voltage and calculating field from the electrode geometry. It is shown here that even with plane parallel electrodes the field can differ markedly from the ideal case because the electric field in a liquid insulator is defined by both the electrode geometry and by the space charge dynamics within the fluid.

\section{REFERENCES}

1. E. C. Cassidy, W. E. Anderson, and S. R. Booker, IEEE Trans. Instrum. Meas. IM-21, 504 (1972).

2. E. A. Cherney and J. D. Cross, IEEE Trans. Elec. Insul. EI-8, 10 (1973). 
3. Z. Croitoru, Progress in Dielectrics, Academic Press, Inc., New York, N. Y., 1965, Vol. 6, pp. 103-146.

4. H. H. Woodson and J. R. Melcher, Electromechanical

Dynamics, J. Wiley and Sons, Inc., New York, N.Y., 1968, Vol. II, Chap. 7, p. 383.

5. N. J. Felici, Direct Current 2, 147 (1971).

6. W. R. L. Thomas, Proc. 4th Int. Conf. on Conduction and Breakdown in Dielectric Liquids, Dublin, 1972, p. 73.

7. Y. Kawaguchi, H. Murata, and M. Ikeda, IEEE Trans. Power Appar. Sys. PAS-91, 9 (1972). 
NBS-IIAA (REV. 7.73)

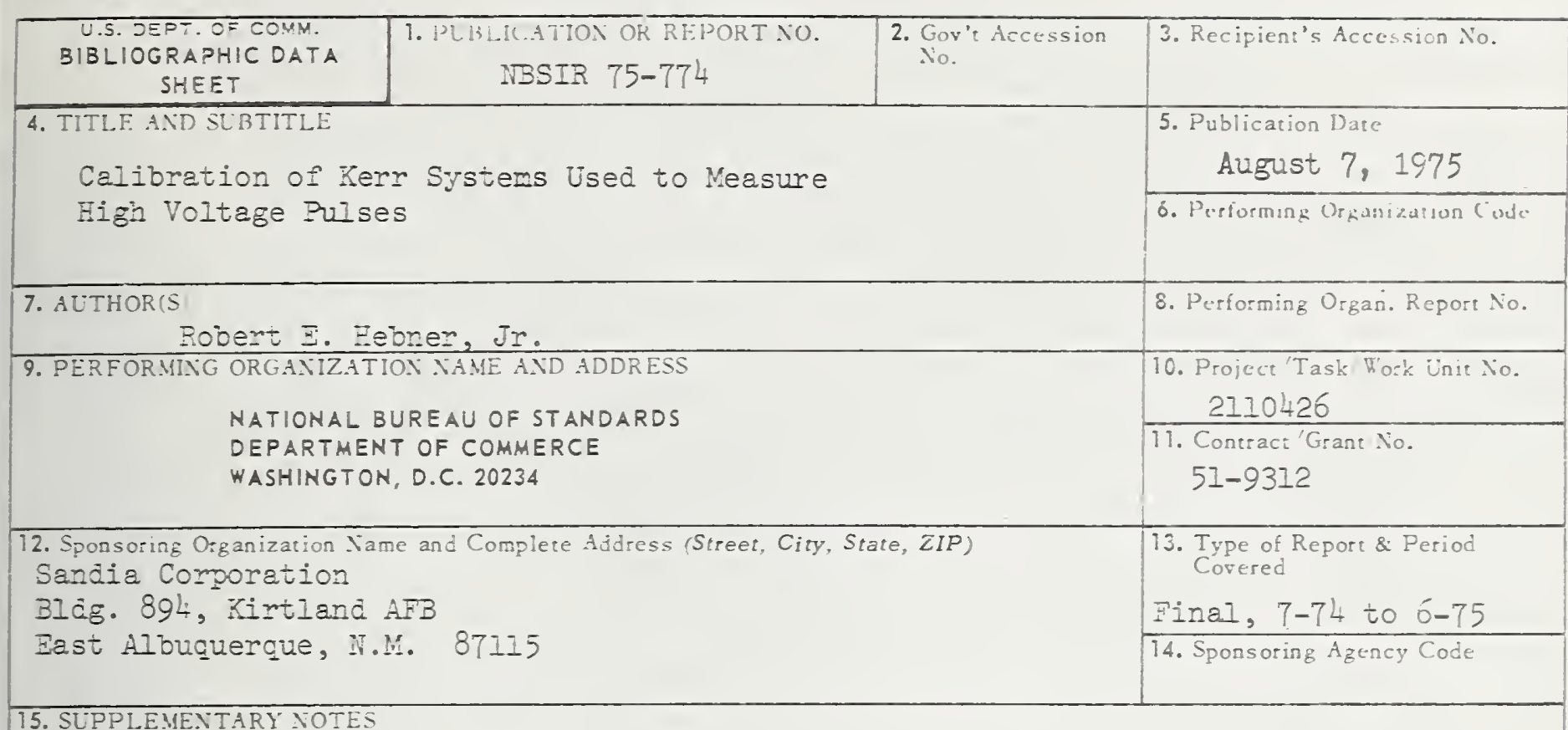

15. SUPPIEMENTARY NOTES

16. ABSTRACT (A 200-word or less factual summary of most significant in formation. If document includes a significant bibliography or literature survey. mention it here.)

The purpose of this work is to define, develop and refine techniques for calibrating pulse voltage measurement systems, particularly those based on the electro-optic Kerr effect. The approach used exploits the assumed Irequency independence of the Kerr coeficient of nitrobenzene. Theoretically, the Kerr coefficient should exhibit the same frequency dependence as the relative permittivity. Yeasurements have show the relative permittivity to be aporoximately frequency incependent over the frequency range irom direct voltage to $10^{9} \mathrm{Fz}$. The realization of this calibration approach has been hampered by the fact that the electric field distribution, in the liquid exhibiting the electro-ootic Kerr effect, is itself frequency dependent.

This report describes the present best comparison of cell calibration under direct voltage with calibration under low Irequency alternating voltage and calibration under pulsed high voltage. The results under all three types of waveforms agree to within $=0.5 \%$. From these results it can be inferred that it is ieasible to use an electrooptic Kerr system as an independent, and possibly more accurate, device against which to calibrate other pulse voltage measurement systems.

In adition to this aiscussion of Kerr system calibration, the report contains fwo appendices. One presents an improved technique for analjsis of data obtained from a Kerr system and the other discusses space charge in a nitrobenzene-filled Kerr cell.

17. NEY WORDS (six to trelve entries; alphabetical order; capitalize only the first letter of the first key word unless a proper name; separated by semicolons) Automated measurements; dielectrics; dividers; electric fielas; electrical measurement; electro-optics; high voltage measurements; insulating fluids; Zerr effect; nitrobenzene; pulse measurements; space charge

18. AVAILABILITY $\sqrt{x}$ Unlimited

For Official Distribution. Do Nor Release to NTIS

- Order From Sup. of Doc., U.S. Government Printing Office

Vlashington, D.C. 20402, SD Cat. No.C13

X Order From National Technical Information Service (NTIS) Springfield, Virginia 22151

\begin{tabular}{|l|c|}
\hline $\begin{array}{l}\text { 19. SECURITY CLASS } \\
\text { (THIS REPURT) }\end{array}$ & 21. NO. OF PAGES \\
UNCLASSIFIED & 50 \\
\hline $\begin{array}{l}\text { 20. SECURITY CLASS } \\
\text { (THIS PAGE) } \\
\text { UNCLASSIFIED }\end{array}$ & 22. P.ice \\
$\$ \mathbf{5} .75$ \\
\hline
\end{tabular}




